\title{
Journal of

\section{Structure-Based Optimization of Potent, Selective, and Orally Bioavailable CDK8 Inhibitors Discovered by High-Throughput Screening}

Paul Czodrowski, ${ }^{* \dagger}{ }^{\dagger}$ Aurélie Mallinger, ${ }^{\dagger}$ Dirk Wienke, $^{\dagger}$ Christina Esdar, $^{\dagger}$ Oliver Pöschke, $^{\dagger}$ Michael Busch, $^{\dagger}$ Felix Rohdich, ${ }^{\dagger}$ Suzanne A. Eccles, ${ }^{\neq}$Maria-Jesus Ortiz-Ruiz, ${ }^{\ddagger}$ Richard Schneider, ${ }^{\dagger}$ Florence I. Raynaud, ${ }^{\ddagger}$ Paul A. Clarke, ${ }^{\ddagger}$ Djordje Musil, ${ }^{\dagger}$ Daniel Schwarz, ${ }^{\dagger}$ Trevor Dale, ${ }^{\S}$ Klaus Urbahns, ${ }^{\dagger}$ Julian Blagg, ${ }^{\dagger}$ and Kai Schiemann $*{ }^{\dagger} \dagger$

${ }^{\dagger}$ Merck KGaA, Frankfurter Strasse 250, Darmstadt, 64293, Germany

${ }^{\ddagger}$ Cancer Research UK Cancer Therapeutics Unit at The Institute of Cancer Research, London, SW7 3RP, U.K.

${ }^{\S}$ School of Bioscience, Cardiff University, Cardiff, CF10 3AX, U.K.

\section{Supporting Information}

ABSTRACT: The mediator complex-associated cyclin dependent kinase $\mathrm{CDK} 8$ regulates $\beta$-catenin-dependent transcription following activation of WNT signaling. Multiple lines of evidence suggest CDK8 may act as an oncogene in the development of colorectal cancer. Here we describe the successful optimization of an imidazo-thiadiazole series of CDK8 inhibitors that was identified in a high-throughput screening campaign and further progressed by structure-based design. In several optimization cycles, we improved the microsomal stability, potency, and kinase selectivity. The initial imidazo-thiadiazole scaffold was replaced by a 3-methyl$1 \mathrm{H}$-pyrazolo[3,4- $b]$-pyridine which resulted in compound $\mathbf{2 5}$ (MSC2530818) that displayed excellent kinase selectivity, biochemical and cellular potency, microsomal stability, and is orally bioavailable. Furthermore, we demonstrated modulation of phospho-STAT1, a pharmacodynamic biomarker of CDK8 activity, and tumor growth inhibition in an APC mutant SW620 human colorectal carcinoma xenograft model after oral administration. Compound 25 demonstrated suitable potency and selectivity to progress into preclinical in vivo efficacy and safety studies.

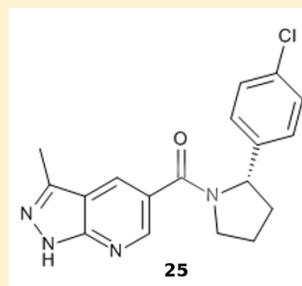

CDK8 IC $502.6 \mathrm{nM}$ Human PK Prediction: $\mathrm{Cl} \sim 0.14 \mathrm{~L} / \mathrm{h} / \mathrm{kg}$
$\mathrm{t} \sim 2.4 \mathrm{~h}$ $\mathrm{F}>75 \%$

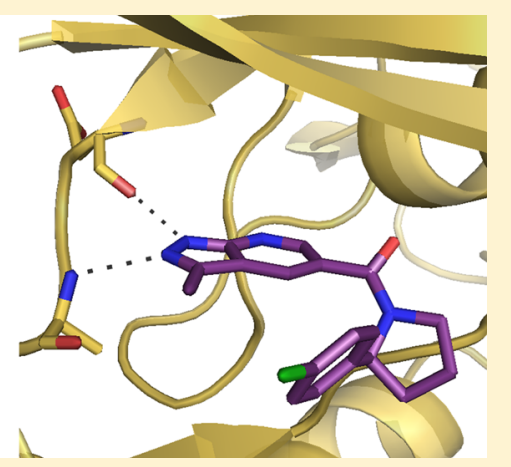

\section{INTRODUCTION}

In contrast to other members of the CDK family (e.g., CDK1, CDK2, and CDK4/6), neither CDK8 nor its paralogue CDK19 are required for the regulation of cell cycle progression. Instead, CDK8 and CDK19 together with MED12/12L and MED13/ $13 \mathrm{~L}$ respectively form a regulatory kinase module for the mediator complex. ${ }^{1,2}$ The mediator complex is a large protein assembly that couples gene-specific transcriptional regulators to the general RNA polymerase II transcription machinery. ${ }^{2-7}$ CDK8 and CDK19 participate in the regulation of transcription through phosphorylation of RNA polymerase $\mathrm{II}^{8}$ and other transcription factors to regulate their activity or tag them for proteosomal degradation. . $^{-14}$

The role of CDK19 in cellular biology and human disease is not well understood and is the subject of ongoing investigation. ${ }^{1}$ However, in contrast, CDK8 is much better characterized and has been proposed to act as an oncogene in colon cancer ${ }^{15}$ and approximately $60 \%$ of colorectal cancers have increased $C D K 8$ gene copy number. ${ }^{16}$ Moreover, a worse prognosis in colon, breast, and ovarian cancer is linked to increased CDK8 expression. ${ }^{17}$ CDK8 is also essential for cell proliferation in melanoma. ${ }^{18}$ Additional cancer-relevant activities of CDK8 include growth factor-induced transcription, modulation of TGF $\beta$-signaling, ${ }^{13}$ and phosphorylation of the Notch intracellular domain. ${ }^{19,20}$ Although knockout of CDK8 prevents embryonic development due to its essential role in the pluripotent stem cell, other studies have reported that CDK8 depletion does not affect the growth of normal cells. ${ }^{15,21,22}$

CDK8 may also contribute to tumorigenesis through activation of $\beta$-catenin regulated gene expression, ${ }^{16}$ a core transcriptional regulator of canonical WNT signaling. Consistent with this observation, expression of the CDK8 gene is correlated with activation of $\beta$-catenin in colon and gastric cancers. ${ }^{17,23}$ Because of its involvement as a regulator of WNT/ $\beta$-catenin signaling, CDK8 may be linked with disorders and diseases in which activation of $\mathrm{WNT} / \beta$-catenin is crucial such

Received: April 20, 2016

Published: August 4, 2016 
as hyperproliferative, inflammatory, or degenerative disorders and several malignant diseases. ${ }^{19,20}$

An extensive contemporary review reports the current status of small-molecule inhibitors for CDK8/CDK19 and highlights an increasing interest in targeting $\mathrm{CDK} 8 ;{ }^{24}$ in addition, a recent report demonstrates a potential use for CDK8 inhibitors in AML. ${ }^{25}$ We recently described the discovery of small-molecule inhibitors of CDK8 from a cell-based high-throughput screen (HTS) seeking WNT signaling inhibitors and also reported additional differentiated series of CDK8 inhibitors from a scaffold-hopping approach using the biochemical screen reported herein. ${ }^{26-30}$ Here we describe the identification of a novel CDK8/19 chemotype from a biochemical HTS versus CDK8 and its subsequent optimization, enabled by structurebased design, to give compound 25 , a potent, selective, and orally bioavailable CDK8/19 ligand suitable for further progression into preclinical studies.

\section{RESULTS AND DISCUSSION}

In a CDK8 high-throughput screen using a FRET-based Lanthascreen binding competition assay, ${ }^{27}$ we identified several hit compounds with submicromolar activity. Our hit series contained an imidazo $[5,1-b][1,3,4]$ thiadiazole scaffold, henceforth described as the "imidazo-thiadiazole" series. Initial hits bore either a 2 -substituted benzyl substituent ( 1 and 2 ) or a 2phenylpyrrolidine ring ( 3 and 4 ) attached to the imidazothiadiazole scaffold via an amide bond at the 2-position (Table 1 ). As a cellular readout of WNT signaling, we used our

\section{Table 1. HTS Hits from the "Imidazo-thiadiazole" Series}

\begin{tabular}{|c|c|c|c|c|c|c|}
\hline \multirow{2}{*}{ ID } & \multirow{2}{*}{ Structure } & \multirow{2}{*}{$\begin{array}{c}\mathrm{CDK}^{\mathrm{I}} \mathrm{IC}_{50} \\
{[\mathrm{nM}]}\end{array}$} & \multirow{2}{*}{$\begin{array}{c}7 \mathrm{dF} 3 \mathrm{IC}_{50} \\
{[\mathrm{nM}]}\end{array}$} & \multicolumn{3}{|c|}{$\mathrm{CL}_{\text {int }}[\mu \mathrm{L} / \mathrm{min} / \mathrm{mg}]$} \\
\hline & & & & Human & Rat & Mouse \\
\hline 1 & & $129 \pm 27$ & $1650 \pm 495$ & $>1000$ & 435 & 119 \\
\hline 2 & & $781 \pm 114$ & $2450 \pm 778$ & 61 & 38 & $>1000$ \\
\hline 3 & & $77 \pm 4$ & $415 \pm 262$ & 56 & 446 & 145 \\
\hline 4 & & $60 \pm 6$ & $290 \pm 141$ & 38 & 280 & 129 \\
\hline
\end{tabular}

previously described $7 \mathrm{dF} 3 \mathrm{WNT}$-specific reporter gene assay ${ }^{31}$ and observed a 3-13-fold drop off from in vitro CDK8 binding affinity to cell-based activity for compounds $\mathbf{1 - 4}$.

Introduction of a methyl group to the alkyl linker resulted in a 6-fold drop in biochemical potency (compound 2, Table 1), and the pyrrolidine moiety was favored over an alkyl chain linker by virtue of significantly increased cell-based potency and improved metabolic stability (compounds 3 and 4). Hydrogen to fluorine exchange at the para position of the phenyl ring (compounds 3 to 4) did not influence biochemical or cell-based potency; however, we noted a slight improvement in microsomal stability (Table 1 ). To further explore the impact of the para-substitution and stereochemistry at the pyrrolidine 2-position, the racemic form and both of the enantiomers bearing a $p$-Cl-phenyl were synthesized (Table 2). The racemic form (5) showed modest biochemical and cell-based activity. Interestingly, the $S$-enantiomer (6) was significantly more
Table 2. Determination of Optimal Pyrrolidine Stereochemistry

\begin{tabular}{|c|c|c|c|c|c|c|}
\hline \multirow{2}{*}{ ID } & \multirow{2}{*}{ Structure } & \multirow{2}{*}{$\begin{array}{c}\mathrm{CDK} \mathrm{IIC} \mathrm{C}_{50} \\
{[\mathrm{nM}]}\end{array}$} & \multirow{2}{*}{$\begin{array}{c}7 \mathrm{dF} 3 \mathrm{IC}_{50} \\
{[\mathrm{nM}]}\end{array}$} & \multicolumn{3}{|c|}{$\mathrm{CL}_{\text {int }}[\mu \mathrm{L} / \mathrm{min} / \mathrm{mg}]$} \\
\hline & & & & Human & Rat & Mouse \\
\hline 5 & & $17 \pm 0.02$ & $100 \pm 28$ & 52 & 719 & 388 \\
\hline 6 & & $3.8 \pm 1.9$ & $70 \pm 14$ & 49 & 655 & 447 \\
\hline 7 & & $110 \pm 15$ & $1,600 \pm 0$ & 60 & 449 & 514 \\
\hline
\end{tabular}

active than the $R$-enantiomer (7); however, the microsomal stability of both enantiomers was in the same range.

To understand the binding mode and to inform further medicinal chemistry design, we determined the crystal structure of the most potent enantiomer (6) bound to CDK8/cyclin C (Figure 1A). Compound $\mathbf{6}$ is bound to the hinge region of CDK8 (Ala100) via the nitrogen atom at the 6-position of the "imidazo-thiadiazole" scaffold, while the 5-methyl group points away from the gatekeeper residue (Phe97) toward the solventexposed channel. The carbonyl group of the C2-amide forms a cation $-\pi$ interaction to the catalytic lysine residue (Lys52), too distant (3.6 $\AA$ ) to be considered as a hydrogen bond. The sulfur atom of the "imidazo-thiadiazole" scaffold is positioned to form favorable van der Waals (vdW) interactions to the gatekeeper residue Phe97. The pyrrolidine ring also forms favorable vdW interactions to Tyr32 and the side chain of Asp173. Furthermore, the orientation of the pyrrolidine defines the exit vector for the $p$-Cl-phenyl substituent which itself forms vdW interactions with Val27, Tyr32, Val35, Leu158, and Arg356. We did not observe sufficient evidence to support a halogen bond between the chlorine atom and the backbone $\mathrm{C}=\mathrm{O}$ of Val27: the distance is $2.9 \AA$, and the angle between the chlorine atom and the $\mathrm{C}=\mathrm{O}$ functionality of $\mathrm{Val} 27$ is $104.7^{\circ}$.

Comparison of the structure of 6 in $\mathrm{CDK} 8 /$ cyclin $\mathrm{C}$ with our recently published crystal structure of a 3,4,5-trisubstituted-2aminopyridine chemotype ${ }^{27}$ (compound 8, CCT251921) revealed few structural differences in the active site. The CDK8 residues in the ATP binding site with the largest variance between the two crystal structures are shown (Figure 1B). Despite the different modes of ligand-binding, the protein structure is largely conserved. Compounds 6 and $8^{27}$ both form $\mathrm{H}$-bond acceptor interactions with the backbone $\mathrm{NH}$ of hinge residue Ala100 and interact with the catalytic lysine (Lys52) through the amide and lactam carbonyl groups, respectively. However, interaction with the gatekeeper residue Phe97 is mediated by the sulfur atom of the thiadiazole scaffold 6 as opposed to the 3-chloro substituent in compound 8. Most notably, the para-chlorophenyl and $N$-methylindazole rings that project into a similar region in the CDK8 solvent channel are linked to the hinge-binding scaffold through different architectures in the two series (Figure 1B).

We were concerned that the thiadiazole ring may be prone to oxidative metabolism and therefore set out to discover a modified scaffold hop in order to mitigate this risk. In addition, we wished to explore variation of the pyrrolidine ring and its 




(A)

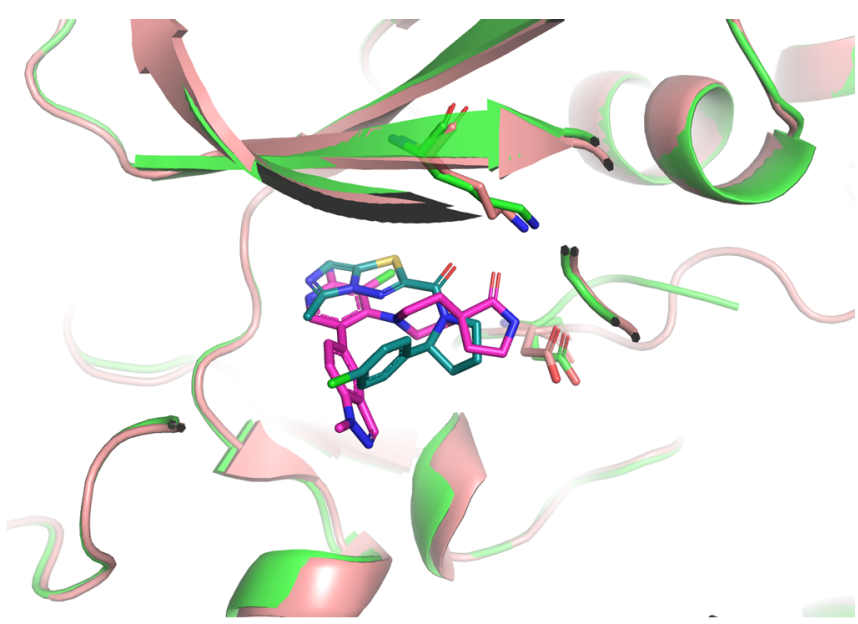

(B)

Figure 1. (A) Crystal structure of CDK8/cyclin C complexed with compound 6 (blue). Hydrogen bonds are displayed as dashed lines. The cationdipole interaction between the carbonyl atom and the catalytic Lys52 is also shown. The key amino acids are given in stick representation. (B) Alignment of the CDK8/cyclin C structures of compound 6 (ligand: blue/protein: salmon) and compound 8 (ligand magenta/protein: green). The residues which deviate most between the two structures are highlighted in stick mode: Lys52, and Asp173. Tyr-32 removed for clarity.

pendant 2-phenyl substituent in order to optimize potency and metabolic stability.

1. Scaffold Hop from the Hinge Binding Motif of the "Imidazo-thiadiazole" Series. We modified the "imidazothiadiazole" scaffold based upon the crystal structure of compound 6 in $\mathrm{CDK} 8 /$ cyclin $\mathrm{C}$ (Figure 1A) according to SZMAP $^{32}$ and WaterMap ${ }^{33}$ analysis (see Figure 2). We ran these calculations for the ligand-deleted form of the crystal structure of compound $\mathbf{6}$ with $\mathrm{CDK} 8 /$ cyclin C. Given this calculation setup, we could analyze the energy of predicted water sites inside the hinge binding region and identify possible handles for scaffold variations.

Solvent ZAP Mapping (SZMAP; ZAP is a PoissonBoltzmann solver) represents a mixture of an implicit and explicit solvent model. In brief, a grid with a spacing of $0.25 \AA$ is generated inside the protein active site and an explicit water molecule is positioned at each grid point with multiple orientations, followed by an implicit solvent PoissonBoltzmann calculation. ${ }^{34,35}$ These calculations can be done with and without the ligand. For our analysis, we performed the calculations without the ligand. Once the calculations are completed for all grid points, an overall energy grid for the presence or absence of water molecules is computed. The predicted water molecules show different characteristics based on their energy values: a water molecule is characterized as "hydrophobic" if its energy value is positive, otherwise it is characterized as "hydrophilic".

The WaterMap methodology is a combination of MD simulation ${ }^{36}$ with the inhomogeneous fluid approach. ${ }^{37}$ In brief, this approach calculates the enthalpic and entropic contributions of binding per predicted water molecule. Consistent with the SZMAP analysis, the ligand was left out for the WaterMap calculations. If the overall free energy per predicted water molecule is positive, it is specified as "unhappy water", whereas a predicted negative free energy indicates a "happy water".

The interpretation of SZMAP and WaterMap calculations can be used for the differentiation of binding modes observed for highly structurally related ligands ${ }^{38}$ and for rationalization of SAR, ${ }^{33,39}$ kinase selectivity, ${ }^{40}$ and binding kinetics. ${ }^{41}$ In the course of our studies, we employed SZMAP and WaterMap for the interpretation of modifications to the hinge binding scaffold. By applying these computational approaches, we explored changes to the five-membered ring of the hinge binding motif and selected a range of 5,6-bicyclic scaffolds for synthesis. The remainder of the molecule was fixed by the $S$ - $p$ Cl-2-phenyl-pyrrolidine motif (Table 3) and compounds were scored by WaterMap, see Figure 2C.

Analysis of the predicted water sites via SZMAP (see Figure 2B) revealed that hydrophilic water molecules are favored directly adjacent to the hinge residues Ala100 and Asp98. This is consistent with the corresponding hydrophilic hinge-binding motifs of our selected scaffold replacements. The remaining part of the hinge-binding region is predicted to be mostly filled with hydrophobic water molecules. Such water molecules can be replaced by both hydrophobic and hydrophilic moieties. $^{42-44}$ On the basis of this finding, we ranked our compound ideas by WaterMap scores. In addition, the characterization of predicted water sites by SZMAP calculations revealed that broad scaffold variations should be possible. The new compound design ideas were also prioritized based upon their synthetic tractability and potential for improved microsomal stability. Figure 2B (lower panel) depicts the contribution from each ligand atom resulting from water molecule replacement at the same position. This analysis underscores the 30-fold difference in CDK8 affinity between compounds 9 and 10: the favorable binding contribution by addition of a methyl group at the 5-position is driven by the replacement of an "unhappy" water molecule; this finding is consistent with both the WaterMap and SZMAP predictions. We performed a ranking of our compounds based on the WaterMap scores for the docking solutions of compounds from Tables 1 and 2 which adopt a similar hinge-binding mode. On the basis of an acceptable trend between WaterMap scores and $\mathrm{pIC}_{50}$, we also scored new compound ideas from Table 3. The outcome of this ranking is given in Figure 2C (lower panel), suggesting a weak correlation between the WaterMap-based analysis and the in vitro potency of compounds from Table 3. We omitted compound $\mathbf{1 1}$ from this analysis because we anticipate a different binding mode; indeed, a 2850-fold decrease in potency was seen with the introduction of an $\mathrm{sp}^{2}$ 


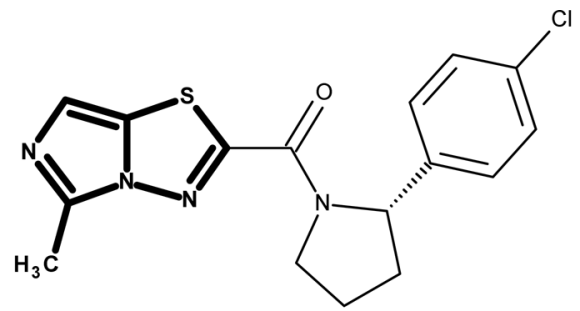

(A)
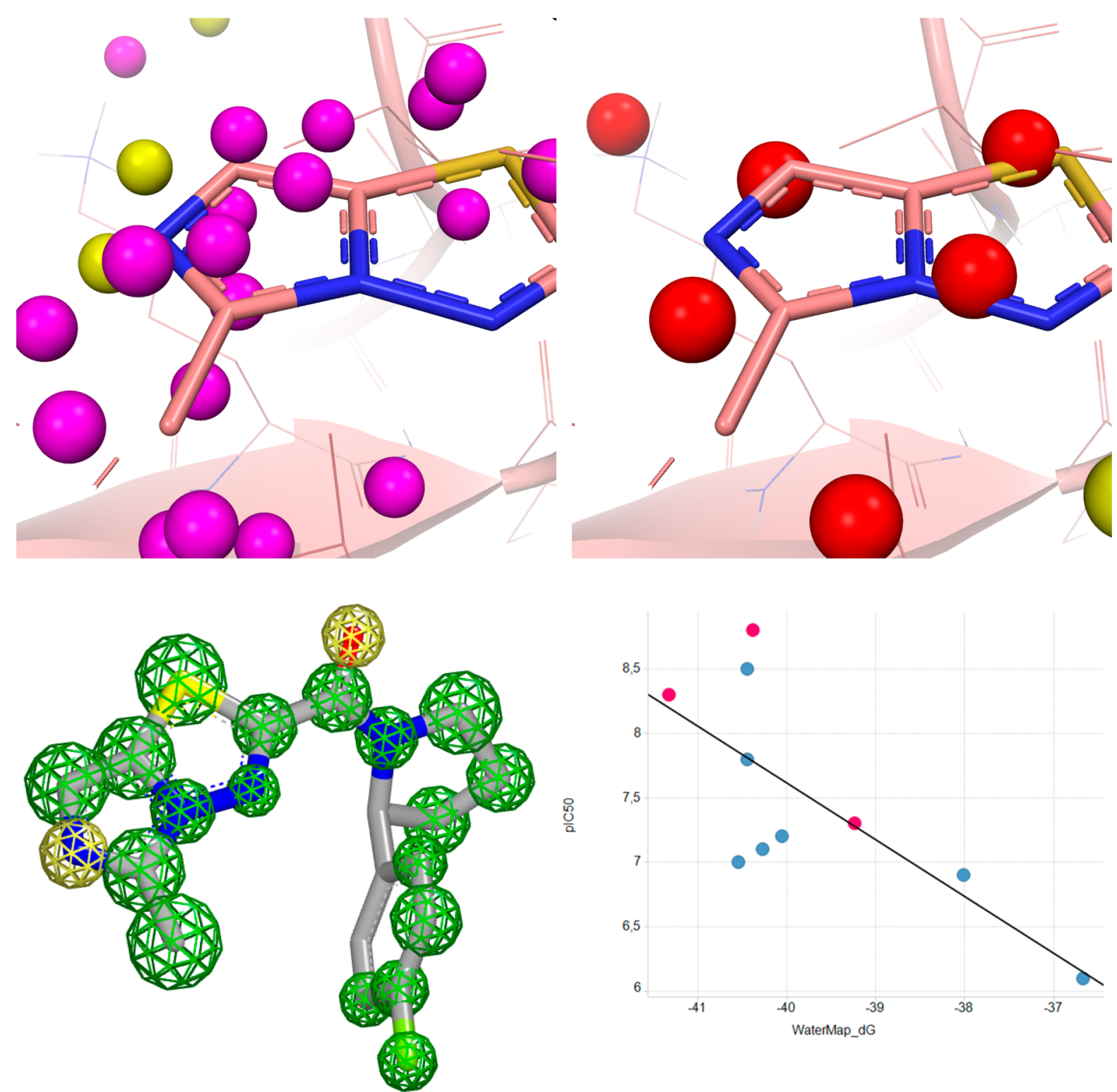

(B)

(C)

Figure 2. (A) SZMAP and WaterMap calculations have been performed for the crystal structure of compound 6 complexed to CDK8/cyclin C. For clarity, only part of the ligand denoted in bold (A) is shown in B and C. (B) Upper panel: Only the hinge region is shown. SZMAP analysis of the CDK8/compound 6 crystal structure: yellow spheres correspond to water sites bearing hydrophilic character and pink spheres correspond to water sites bearing hydrophobic character. Lower panel: The contribution from each ligand atom resulting from water molecule replacement at the same position is shown. The character of the ligand-displaced water spheres are depicted as mesh: yellow mesh corresponds to hydrophilic water spheres and green mesh corresponds to hydrophobic water spheres. The size of the water spheres correspond to the relative energy gain obtained by replacement of the particular water sphere by each ligand atom. (C) Upper panel: Only the hinge region is shown for clarity; the full ligand is depicted in (A). WaterMap analysis of the CDK8/compound 6 crystal structure: red spheres correspond to "unhappy" water molecules and yellow spheres to "happy" water molecules. Lower panel: WaterMap scoring versus CDK8 $\mathrm{pIC}_{50}$ for the compounds from Tables 1 and 2 (blue dots) and the compounds from Table 3 (red dots), $r^{2}=0.54$. 
Table 3. Variation of the Hinge Binding Motif of the "Imidazo-thiadiazole" HTS Scaffold

\begin{tabular}{|c|c|c|c|c|c|c|}
\hline \multirow{2}{*}{ ID } & \multirow{2}{*}{ Structure } & \multirow{2}{*}{$\begin{array}{c}\text { CDK8 IC }{ }_{50} \\
{[\mathrm{nM}]}\end{array}$} & \multirow{2}{*}{$\begin{array}{c}7 \mathrm{dF} 3 \mathrm{IC}_{50} \\
{[\mathrm{nM} \mathrm{M}}\end{array}$} & \multicolumn{3}{|c|}{$\mathrm{CL}_{\text {int }}[\mu \mathrm{L} / \mathrm{min} / \mathrm{mg}]$} \\
\hline & & & & Human & Rat & Mouse \\
\hline 9 & & $32 \pm 33$ & $100 \pm 28$ & 354 & 94 & 86 \\
\hline 10 & & $1.4 \pm 0.1$ & $0.6 \pm 0.004$ & 525 & 79 & 244 \\
\hline 11 & & $3,990 \pm 1,151$ & $>10,000$ & $<10$ & 19 & 18 \\
\hline 12 & & $9 \pm 1$ & $90 \pm 14$ & 390 & 108 & 63 \\
\hline 13 & & $4.9 \pm 0.5$ & $28 \pm 3$ & 23 & 10 & 10 \\
\hline
\end{tabular}

nitrogen atom juxtaposed to the $\mathrm{C}=\mathrm{O}$ backbone group of Asp98, see compound 11, versus the corresponding hydrogen bond donor in compound $\mathbf{1 0}$ (Table 3). However, compound 11 showed good microsomal stability, indicating that an appropriate scaffold hop could significantly improve stability to oxidative metabolism. Pleasingly, the introduction of a methyl group at the 3-position of the indazole $\mathbf{9}$ to give $\mathbf{1 0}$ resulted in a 22 -fold improvement in biochemical potency and a 166-fold increase in cell-based potency; however, no improvement in microsomal stability was observed consistent with the increased lipophilicity of compound $\mathbf{1 0}$ versus $\mathbf{9}$.

In summary, the potency increase arising from introduction of the C3-methyl group in compound $\mathbf{1 0}$ is consistent with our SZMAP analysis (Figure 2B). However, we recognized that the indazole C3-methyl group could be susceptible to oxidative metabolism and therefore introduced a more polar amino group at this position (compound 13), cognizant that improved hinge-binding interaction with the backbone carbonyl of Ala100 may also be realized (Figure 1). This tactic maintained in vitro CDK8 potency and improved microsomal stability as desired but unfortunately led to a 47-fold drop in cellular potency (compared to compound 10) despite good Caco2 flux $\left(P_{\text {appA-B }}\right.$ $=33.7 \times 10^{-6} \mathrm{~cm} \mathrm{~s}^{-1}$ ) and low efflux ratio (2.2).

Compound 13 proved optimal in terms of biochemical potency and metabolic stability and was further profiled in a broad kinase panel to discover any kinase selectivity issues (Supporting Information, Table S2). Five off-target kinases were detected (JAK1, JAK2, JAK3, ROCK-II, and TYK2) and were subject to $\mathrm{IC}_{50}$ determination to confirm potency (Table 4). Consequently, we aimed to improve selectivity versus these off-target kinases in subsequent medicinal chemistry optimization.

2. Variation of the Ring Linker Size and Halogen Substituents. To inform our medicinal chemistry design, we calculated selectivity grids ${ }^{45}$ for the CDK8/compound 6 crystal structure, see Figure $3 \mathrm{~A}$, and selectivity grids for the most notable off-target kinases, see Figure 3B. Selectivity grids
Table 4. Kinase Profile Data for 13 (See Also Supporting Information, Table 2), Sorted Alphabetically

\begin{tabular}{lcc} 
kinase & $\mathrm{IC}_{50}(\mathrm{nM})$ & \% inhibition at $1 \mu \mathrm{M}$ \\
CDK8 & 4.9 & 100 \\
JAK1 & 90 & 86 \\
JAK2 & 286 & 84 \\
JAK3 & 219 & 79 \\
ROCK-II & 1330 & 42 \\
TYK2 & 279 & 70 \\
\hline
\end{tabular}

represent a plausible interpretation of regions within binding pockets which may be targeted to improve (or to lose) selectivity. ${ }^{45}$ These selectivity grids suggested that the parahalogen substituent of the phenyl ring and the 3-amino group of the indazole scaffold represented possible variation points to achieve selectivity for CDK8 over the off-target kinases, see Figure 3A. Furthermore, this analysis suggested that substitution at the solvent-exposed region of the binding pocket would nonspecifically increase potency against the off-target kinases, see Figure 3B. Therefore, we decided to vary the parahalogen substituent as well as the pyrrolidine ring and also to methylate the 3-amino group on the indazole scaffold in order to improve the selectivity and cell-based activity of compound 13 (Tables 3 and 5).

The kinase selectivity data confirmed the hypothesis that the para-substituent could act as selectivity handle: The \% inhibition values, which refer to single point measurements of percent inhibition at $1 \mu \mathrm{M}$, demonstrate that the off-target activity versus the JAK family decreases as the para-halogen substituent is varied from $\mathrm{Br}$ to $\mathrm{Cl}$ to $\mathrm{F}$. Selectivity could be further improved by modifications of the ring linker size or switching from a 1,2-substitution pattern to a 1,3-substitution pattern of the pyrrolidine linker. Pleasingly, the affinity for offtarget kinases was also reduced by methylating the 3 -amino group.

In summary, variation of the halogen substituent in the paraposition of the phenyl ring showed a clear trend: while the ontarget biochemical $\mathrm{CDK} 8$ and cellular $7 \mathrm{dF} 3$ potencies decreased from $\mathrm{Br}$ to $\mathrm{Cl}$ to $\mathrm{F}$ in the matched trio 14, 13, and 15, less potent off-target activity versus the JAK family, ROCKII and TYK2, was also observed. Interestingly, all three compounds were metabolically stable. Replacement of pyrrolidine (15) with azetidine (16) retained biochemical potency and microsomal stability with slight loss in cell-based potency. The same held true when increasing the ring size from a pyrrolidine to a piperidine linker (17) although cell-based potency was further eroded. Alteration of the substitution pattern at the pyrrolidine from 1,2 to 1,3 showed a moderate loss of biochemical and cellular potency (compare 18 with 13) while maintaining good microsomal stability. Finally, the addition of a methyl group to the 3-amino functionality of the indazole scaffold resulted in equipotent biochemical and cellular activity (compare 19 with 13) combined with a slight loss of microsomal stability.

We next determined the crystal structure of compound 17 bound to $\mathrm{CDK} 8 /$ cyclin $\mathrm{C}$ (Figure $4 \mathrm{~A}$ ) and examined the superposition of 17 with compound 6 (Figure 4B). The indazole hinge-binding motif is located at the same position as the "imidazo-thiadiazole" scaffold of 6 . N1 of the indazole scaffold forms an additional hydrogen bond to the $\mathrm{C}=\mathrm{O}$ backbone of Asp98. The carbonyl moiety linking the para-halophenyl piperidine to the hinge-binding scaffold is located at the 

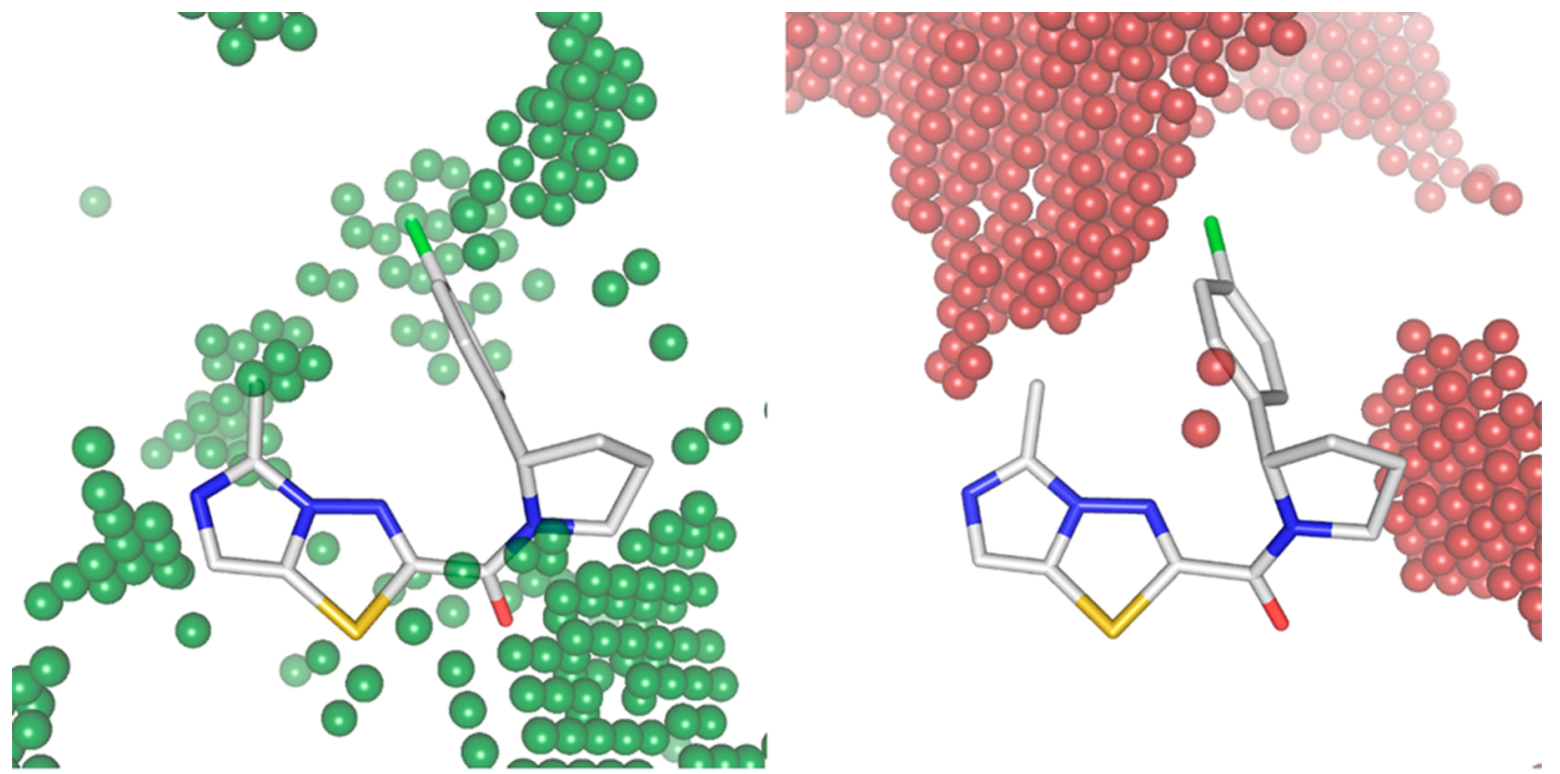

(A)

(B)

Figure 3. (A) Selectivity grids for the CDK8-specific regions of the active site. In general, regions around the para-substituted halogen in the phenyl ring as well as the region adjacent to the pyrrolidine ring can be considered as potential selectivity handles. (B) Selectivity grids of the ATP binding pocket which have the potential to drive increased potency for off-target kinases such as the JAK family.

Table 5. Variations of the Ring Linker Size and para-Substitution of the Phenyl Ring

\begin{tabular}{|c|c|c|c|c|c|c|c|c|c|c|c|c|}
\hline I & \multirow{2}{*}{ Structure } & CDK8 & JAK1 & JAK2 & JAK3 & ROCK-II & TYK2 & CDK8 & $7 \mathrm{dF} 3$ & \multicolumn{3}{|c|}{$\mathrm{CL}_{\text {int }}[\mu \mathrm{L} / \mathrm{min} / \mathrm{mg}]$} \\
\hline & & \multicolumn{6}{|c|}{$\%$ inhibition at $1 \mu \mathrm{M}$} & \multicolumn{2}{|c|}{$\mathrm{IC}_{50}[\mathrm{nM}]$} & Human & Rat & Mouse \\
\hline 14 & & 98 & 88 & 88 & 76 & 65 & 76 & $3.1 \pm 1$ & $19 \pm 4$ & $<10$ & $<10$ & 14 \\
\hline 15 & & 93 & 72 & 59 & 58 & 27 & 62 & $32 \pm 0.4$ & $120 \pm 14$ & $<10$ & $<10$ & $<10$ \\
\hline 16 & & 94 & 63 & 24 & 21 & 12 & 45 & $49 \pm 6$ & $435 \pm 163$ & 10 & $<10$ & 10 \\
\hline 17 & & 95 & 21 & -2 & -14 & 22 & 17 & $45 \pm 3$ & $800 \pm 283$ & $<10$ & 15 & 28 \\
\hline 18 & & 96 & 24 & -14 & 15 & 20 & 23 & $24 \pm 6$ & $150 \pm 14$ & $<10$ & 26 & 19 \\
\hline 19 & & 99 & 34 & 34 & 37 & 17 & 32 & $5.4 \pm 3$ & $12 \pm 6$ & 18 & 28 & 31 \\
\hline
\end{tabular}

same position in both ligands. Interestingly, the exocyclic amino group in the 3-position of the indazole does not form a hydrogen bond with the backbone carbonyl atom of Ala100 (the heavy atom distance $=3.4 \AA$ ) and the electron density surrounding this amino group is not consistent with the placement of a water molecule. These observations are 

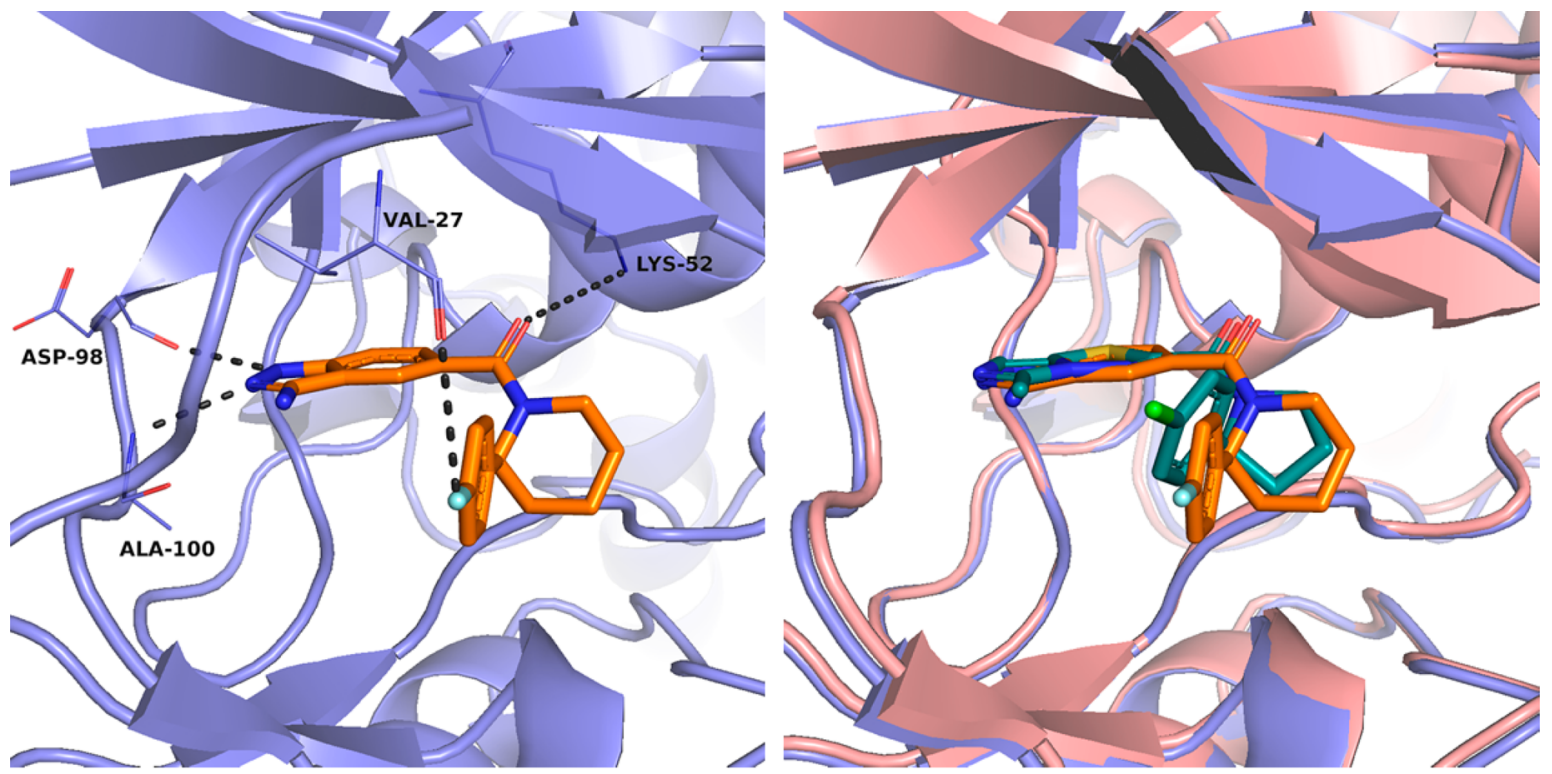

(A)

(B)

Figure 4. (A) Crystal structure of $\mathbf{1 7}$ (orange) in complex CDK8/cyclin C. The hydrogen bonds are indicated by black dotted lines. (B) Superposition of crystal structures of compounds 17 (orange) and 6 (blue).

consistent with SZMAP and WaterMap calculations that did not predict an energetically favorable water molecule in this region. Compound 6 was 12 -fold more potent than 17 versus $\mathrm{CDK} 8$, and we reasoned that this difference may be driven by the halogen substituent; indeed, comparison of the matched molecular pair 15 and 17, which only differ by the ring linker size (pyrrolidine vs piperidine), were equipotent (32 vs 45 $\mathrm{nM}$ ). Although the ring size is increased from a five-membered pyrrolidine linker to a six-membered piperidine linker, the $p-\mathrm{F}$ phenyl ring is placed at an almost identical position compared to compound 6, see Figure 4B. Comparing the fluorine atom (compound 17) to the chlorine atom (compound 6), the halogen to Val27 carbonyl distance is increased from $2.9 \AA$ (compound 6, chlorine) to $3.7 \AA$ (compound 17, fluorine). We observed only one other structural difference: the distance between the carbonyl linker and the catalytic lysine Lys52 (3.6 $\AA$ for compound 6 and $4.6 \AA$ for compound 17). Thus, we attribute the increased potency of compound 6 to the improved interaction of the para- $\mathrm{Cl}$ atom with Val27 compared to the para-F atom in compound $\mathbf{1 7}$ together with improved interaction between the carbonyl linker and Lys52 for compound 6.

Although we had improved the kinase selectivity and maintained microsomal stability by variations of the pyrrolidine linker and para-halogen substituent, the resultant compounds (16 and 17) lacked the desired biochemical potency and cellular activity. Comparison of the matched molecular pair C3amino with C3-methyl (13 vs 10) indicated that the C3-methyl substitution resulted in good cellular potency, albeit with poorer microsomal stability. Consequently, we selected the C3methylindazole scaffold for further progression.

3. Optimization of Microsomal Stability. In vitro metabolite identification studies indicated that the pyrrolidine ring linker is the major site of oxidative metabolism for compound 10. Thus, we prepared close analogues of compound 10 with reduced overall lipophilicity with the aim of improving metabolic stability (Table 6).
Table 6. Variations of the Ring Linker Size Based on the 3Methyl-indazole Scaffold

\begin{tabular}{|c|c|c|c|c|c|c|}
\hline \multirow{2}{*}{ ID } & \multirow{2}{*}{ Structure } & \multirow{2}{*}{$\begin{array}{c}\text { CDK8 IC } C_{50} \\
{[\mathrm{nM}]}\end{array}$} & \multirow{2}{*}{$\begin{array}{c}7 \mathrm{dF} 3 \mathrm{IC}_{50} \\
{[\mathrm{nM}]}\end{array}$} & \multicolumn{3}{|c|}{$\mathrm{CL}_{\text {int }}[\mu \mathrm{L} / \mathrm{min} / \mathrm{mg}]$} \\
\hline & & & & Human & Rat & Mouse \\
\hline 20 & & $1.7 \pm 0.1$ & $2.0 \pm 0.4$ & 908 & 62 & 113 \\
\hline 21 & & $15 \pm 2$ & $230 \pm 14$ & 135 & 40 & 63 \\
\hline 22 & & $8.5 \pm 2$ & $115 \pm 7$ & 135 & 44 & 29 \\
\hline
\end{tabular}

Replacement of the pyrrolidine by an azetidine (compound 20) did not lead to improved metabolic stability in all species; however, the racemic piperazine and morpholine derivatives (21 and 22, respectively) resulted in improved $\mathrm{CL}_{\text {int }}$ profiles across all species. Disappointingly, we observed a decrease in the biochemical CDK8 affinity and the cellular potency (Table 6).

In summary, the microsomal stability could be improved by reducing overall lipophilicity; however, a corresponding drop in biochemical and cell-based activity was also observed. Therefore, we attempted to improve the metabolic stability by reducing the lipophilicity of the molecule through the introduction of polarity into the hinge-binding scaffold.

4. Fine-Tuning of the Hinge Binding Motif. The pyrazole hinge binding motif was fixed and the six-membered ring of the indazole scaffold was varied by introduction of single nitrogen atoms in the 4-, 6-, and 7-positions to reduce the overall lipophilicity of the scaffold (compounds 23-25, Table 
7). Introduction of a nitrogen atom at the 6-position of the indazole ring (23) resulted in a significant drop in biochemical

Table 7. Fine-Tuning of the Hinge Binding Motif

\begin{tabular}{|c|c|c|c|c|c|c|}
\hline \multirow{2}{*}{ ID } & \multirow{2}{*}{ Structure } & \multirow{2}{*}{$\begin{array}{c}\mathrm{CDK} \mathrm{IC}_{50} \\
{[\mathrm{nM}]}\end{array}$} & \multirow{2}{*}{$\begin{array}{c}7 \mathrm{dF} 3 \mathrm{IC}_{50} \\
{[\mathrm{nM}]}\end{array}$} & \multicolumn{3}{|c|}{$\mathrm{CL}_{\text {int }}[\mu \mathrm{L} / \mathrm{min} / \mathrm{mg}]$} \\
\hline & & & & Human & Rat & Mouse \\
\hline 23 & & $11 \pm 1.6$ & $125 \pm 35$ & 206 & 70 & 61 \\
\hline 24 & & $1.3 \pm 0.06$ & $2.8 \pm 0.4$ & 100 & 69 & 29 \\
\hline 25 & & $2.6 \pm 0.1$ & $6.5 \pm 2$ & 45 & $<10$ & $<10$ \\
\hline
\end{tabular}

and cell-based potency. Nitrogen at the 4-position of the indazole ring gave the most potent analogue (24); however, this compound showed only modest microsomal stability. Pleasingly, introduction of a nitrogen atom at the 7-position (25) resulted in acceptable biochemical CDK8 affinity and furthermore showed improved microsomal stability (Table 7).

The matched molecular pair compound 25 versus compound 6, where only the hinge binding scaffold ("pyrazolo-pyridine" vs "imidazo-thiadiazole") has been changed, showed equivalent biochemical CDK8 affinity and a 11-fold improvement in cellbased potency together with a significant improvement in mouse and rat microsomal stability.

We next determined the crystal structure of 25 bound to CDK8/cyclin C (Figure 5A). The carbonyl atom at C5 of the azaindazole scaffold of $\mathbf{2 5}$ forms a hydrogen bond to Lys52 and the side chain of Lys 52 moves toward the ligand in comparison to the binding mode of compound 6 in CDK8/cyclin C (Figure
$5 B)$. Overall, the orientation of the active site residues is well conserved between the crystal structures of 25 and 6 . The interaction pattern is identical except for an additional favorable interaction from the N1-indazole hydrogen bond donor to the backbone $\mathrm{C}=\mathrm{O}$ atom of Asp98 for 25. Notably, the additional nitrogen atom at the 7-position of the indazole scaffold does not elicit any additional favorable interactions consistent with the corresponding biochemical potencies: indazole 10 (CDK8 $\left.\mathrm{IC}_{50}=1.4 \mathrm{nM}\right)$ versus aza-indazole $25\left(\mathrm{CDK} 8 \mathrm{IC}_{50}=2.6 \mathrm{nM}\right)$.

In a commercially available reporter displacement assay, ${ }^{46}$ compound 25 binds to CDK8 and CDK19 with similar affinity (4 $\mathrm{nM}$ ), as we have previously observed across multiple chemotypes, $^{27-30}$ with residence times of 18 and $32 \mathrm{~min}$, respectively. Potent inhibition of phospho-STAT1 ${ }^{\text {SER727, an }}$ established biomarker of CDK8 activity, ${ }^{29}$ in SW620 human colorectal carcinoma cells was also observed (pSTAT1 ${ }^{\text {SER727 }}$ $\mathrm{IC}_{50}=8 \pm 2 \mathrm{nM}$ ). Furthermore, compound 25 demonstrated potent inhibition of WNT-dependent transcription in human cancer cell lines that have constitutively activated WNT signaling. For example, 25 inhibited the reporter-based luciferase readout in several cell lines bearing activating WNT-pathway mutations; LS174T $\left(\beta\right.$-catenin mutant, $\mathrm{IC}_{50}=$ $32 \pm 7 \mathrm{nM}$ ), COLO205 (APC mutant, $\mathrm{IC}_{50}=9 \pm 1 \mathrm{nM}$ ) and demonstrated inhibition of WNT3a ligand-dependent reporter readout in PA-1 cells $\left(\mathrm{IC}_{50}=52 \pm 30 \mathrm{nM}\right)$. Compound 25 demonstrated minimal activity in the CEREP panel, being active on the dopamine transporter $\left(\mathrm{IC}_{50}=8.5 \mu \mathrm{M}\right)$ as the only activity below $10 \mu \mathrm{M}$, and demonstrated minimal hERG inhibition (18\%@10 $\mu \mathrm{M})$. Testing against a 264 kinase panel gave inhibition of only a single kinase by more than $50 \%$ at 1 $\mu \mathrm{M}\left(\mathrm{GSK} 3 \alpha \mathrm{IC}_{50}=691 \mathrm{nM}\right)$. Furthermore, compound 25 is a soluble CDK8 inhibitor (kinetic solubility $>200 \mu \mathrm{M}$; thermodynamic solubilities: $0.399 \mathrm{mg} / \mathrm{mL}$ (PBS, $\mathrm{pH}$ 7.4), $0.628 \mathrm{mg} / \mathrm{mL}$ (FaSSIF, pH 6.5), and $0.836 \mathrm{mg} / \mathrm{mL}$ (FeSSIF, $\mathrm{pH} 5.0))$ with high permeability $\left(P_{\mathrm{appA}-\mathrm{B}}=44 \times 10^{-6} \mathrm{cms}^{-1}\right)$ and low efflux ratio in Caco-2 cells $(\mathrm{ER}=1.5)$ and does not inhibit any cytochrome $\mathrm{P} 450$ subtypes (Cyp $\left.\mathrm{IC}_{50} s>20 \mu \mathrm{M}\right)$. In light of its promising in vitro profile, 25 was further profiled in in vivo pharmacokinetic and pharmacological studies. Overall,

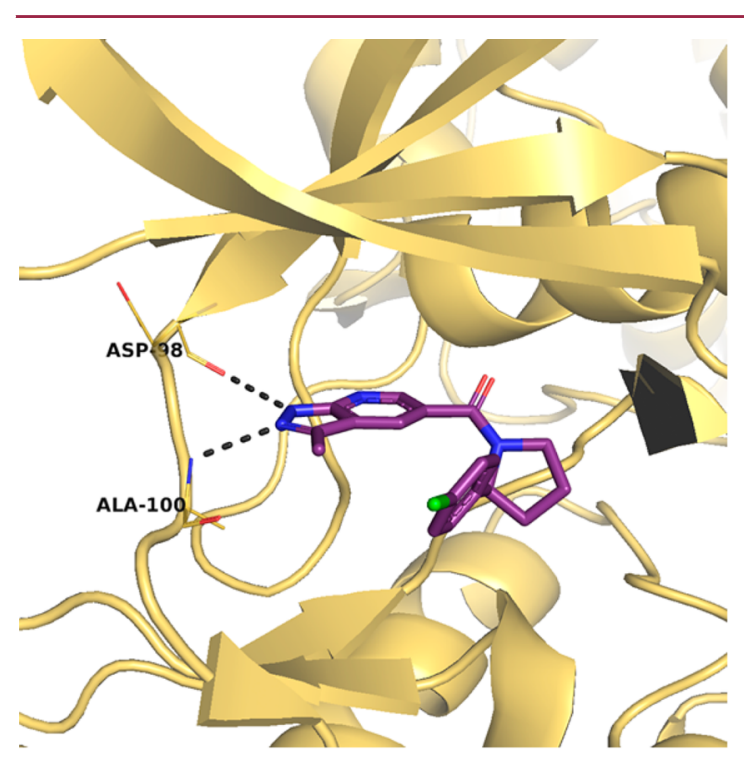

(A)

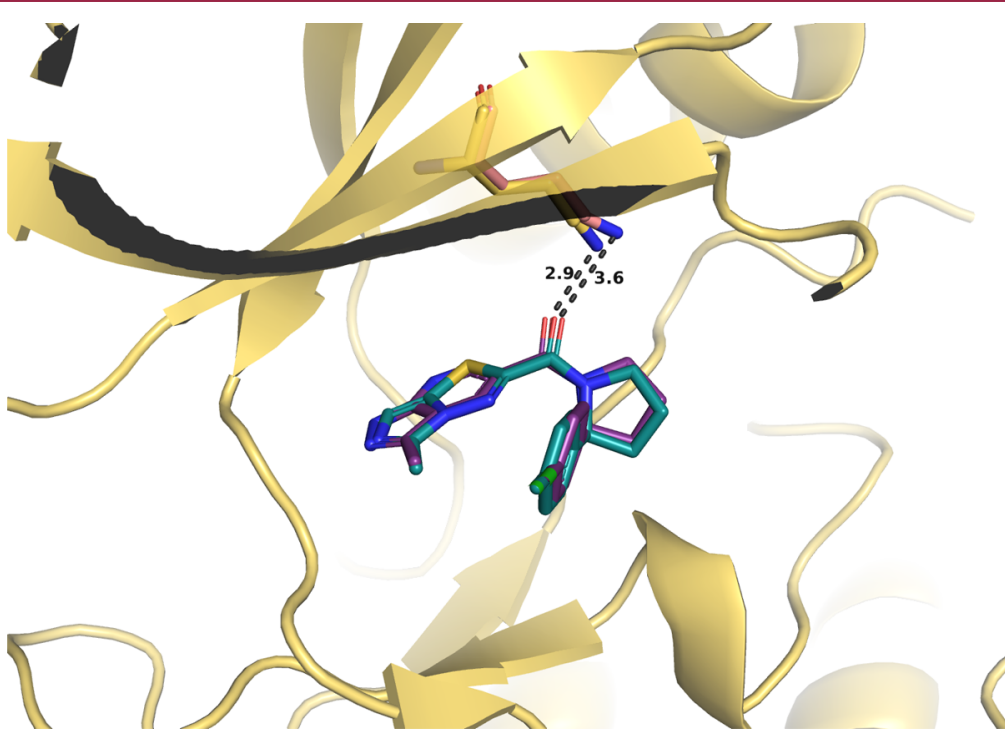

(B)

Figure 5. (A) Crystal structure of $\mathbf{2 5}$ (violet) complexed with CDK8-cyclin C. (B) Superposition of the $\mathbf{2 5}$ (violet) and $\mathbf{6}$ (blue) crystal structures. 
the compound showed acceptable pharmacokinetics (PK) in all tested preclinical species (Table 8 ). Prediction of the human

Table 8. Pharmacokinetic Profile of Compound 25

\begin{tabular}{lcccccc}
\multicolumn{1}{c}{ species } & $\begin{array}{c}f_{\mathrm{u}} \\
(\%)\end{array}$ & $\begin{array}{c}\mathrm{Vd}_{\mathrm{ss}} \\
(\mathrm{L} / \mathrm{kg})\end{array}$ & $\begin{array}{c}\text { plasma Cl } \\
(\mathrm{L} / \mathrm{h} / \mathrm{kg})\end{array}$ & $\% \mathrm{Qh}$ & $t_{1 / 2}(\mathrm{~h})$ & $F$ \\
mouse & 13 & 0.59 & 1.37 & 22.5 & 0.45 & 0.25 \\
rat & 19 & 1.62 & 1.50 & 34.6 & 0.86 & 0.66 \\
$\operatorname{dog}$ & 50 & 1.47 & 1.35 & 53.8 & 0.83 & 0.39 \\
human & 16 & $\sim 0.48$ & $\sim 0.14$ & 12.1 & $\sim 2.4$ & $>0.75^{a}$
\end{tabular}

${ }^{a}$ Predicted by PBPK modeling (GastroPlus).

PK was performed by three species allometric scaling corrected for protein binding and considering interspecies differences in intrinsic clearance in liver microsomes. The human clearance (CL) and volume of distribution at steady-state $\left(\mathrm{Vd}_{\mathrm{ss}}\right)$ were estimated to be low $(\sim 0.14 \mathrm{~L} / \mathrm{h} / \mathrm{kg})$ and small $(0.48 \mathrm{~L} / \mathrm{kg})$, respectively, resulting in a short predicted terminal half-life $(2.4$ h). Physiologically based pharmacokinetics (PBPK) simulations suggested that human oral bioavailability may be $\geq 75 \%$ up to dose level of $500 \mathrm{mg}$ daily.

Compound 25 was then assessed in vivo in an established SW620 human colorectal cancer xenograft model in female $\mathrm{NCr}$ athymic mice. Tumor-bearing mice were treated orally with compound 25 (50 mg/kg bid or $100 \mathrm{mg} / \mathrm{kg} \mathrm{qd}$ ) for 16 days. Both schedules gave a similar reduction in tumor growth (Figure $6 \mathrm{~A}$ ) with $\mathrm{T} / \mathrm{C}$ ratios (based on final tumor weights) of $49 \%$ and $57 \%$, respectively. The compound was generally well tolerated, with no effects on mouse body weight in the $\mathrm{qd}$ administration schedule and manageable body weight loss with the bid schedule (Figure 6B). We monitored inhibition of STAT1 ${ }^{\text {SER727 }}$ phosphorylation by a Luminex immunoassay; phospho-STAT1 ${ }^{\text {SER727 }}$ levels were reduced to the limits of detection $2 \mathrm{~h}$ after dosing in both administration schedules and remained below the control levels even after $24 \mathrm{~h}$, having more pronounced effects in the bid compared with the qd schedule (Figure 6C).

\section{CONCLUSIONS}

In an HTS campaign using a FRET-based Lanthascreen binding competition assay, we identified a chemical series comprising an imidazo-thiadiazole scaffold with exemplar compounds demonstrating $\mathrm{IC}_{50}$ values in the $60-780 \mathrm{nM}$ range (Table 1); however, this series lacked sufficient microsomal stability. Determination of the crystal structure of compound 6 in $\mathrm{CDK} 8 /$ cyclin $\mathrm{C}$ demonstrated clear differences in binding mode compared to our previously reported 3,4,5 trisubstituted-2-aminopyridine series. ${ }^{27}$ SZMAP and WaterMap calculations were applied to identify potential scaffold replacements to enhance potency and improve metabolic stability. By applying these computational approaches, we explored changes to the skeleton of the five-membered ring of the imidazothiadiazole hinge binding motif and discovered a series of indazole-based scaffold replacements. Notably, 3-methyl indazole 10 demonstrated potent biochemical and cell-based potency; however, insufficient metabolic stability precluded further progression. Replacement of the C3-methyl substituent with a C3-amino group gave compound 13, which demon-

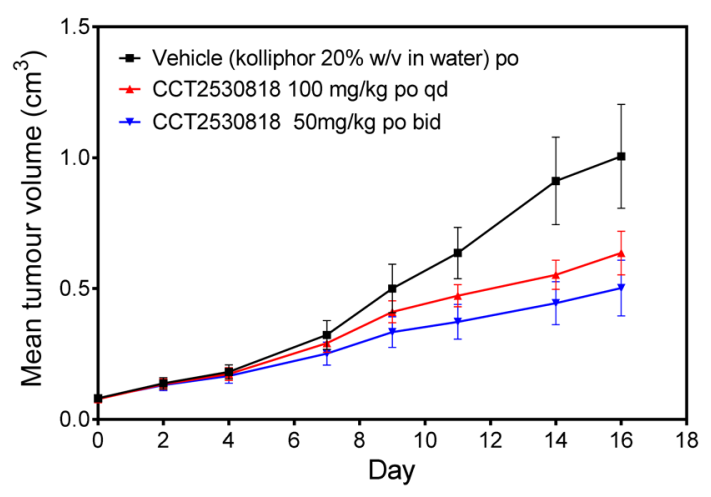

(A)

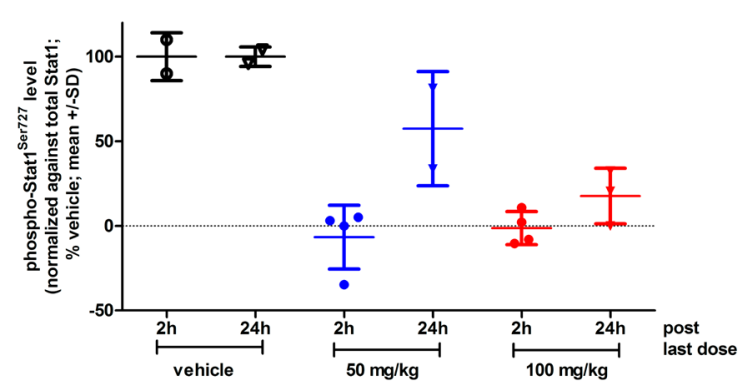

(C)

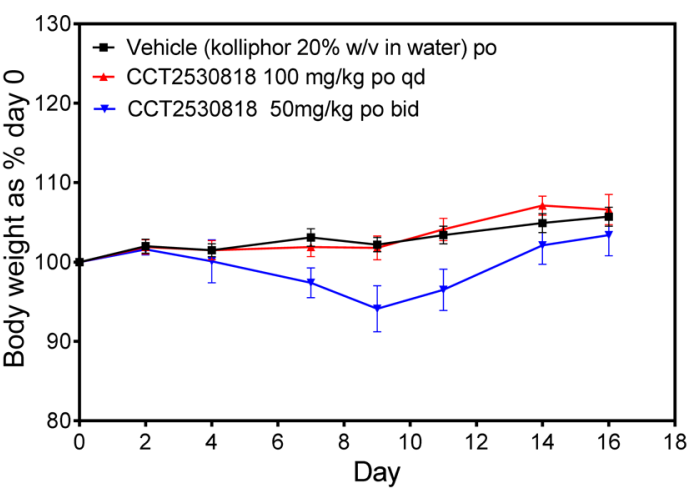

(B)

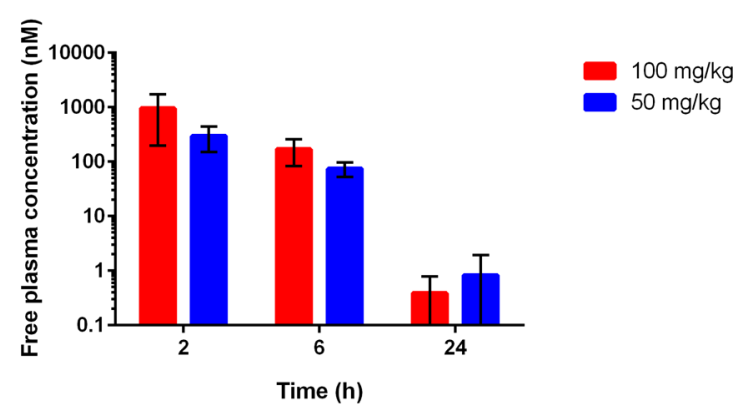

(D)

Figure 6. Efficacy study of compound 25 in SW620 human colorectal cancer xenografts. (A) Tumor growth rates expressed as volumes (mean \pm SEM). (B) Mouse body weights expressed as \% of day 0 values. (C) Phospho-STAT ${ }^{\text {SER727 }}$ levels relative to total STAT1 levels and expressed as $\%$ vehicle controls at each time point. (D) Free plasma concentrations of compound 25 over time at the two dose schedules (50 mg/kg bid or $100 \mathrm{mg} /$ $\mathrm{kg}$ qd). 
strated optimal biochemical potency and metabolic stability but suffered from undesirable off-target kinase affinity.

We employed selectivity grids to rationalize key regions for the modulation of kinase selectivity for the most notable offtarget kinases, and discovered that selectivity could be improved by modifications to the pyrrolidine ring and by variation of the para-halogen substituent on the pendant phenyl ring to give, for example, the selective and metabolically stable para-fluorophenylpiperidine analogue 17 . Crystallization of $\mathbf{1 7}$ in $\mathrm{CDK} 8 /$ cyclin $\mathrm{C}$ revealed a conserved binding mode; however, 17 lacked the desired biochemical potency and cellular activity.

Revisiting the C3-methylindazole series and applying the principle of reduced lipophilicity to abrogate oxidative metabolism enabled the synthesis of potent and selective analogues with improved cell-based potency compared to 3amino-indazole 17. In particular, the 7-azaindole scaffold exemplified by compound $\mathbf{2 5}$, which demonstrated an optimal compromise of biochemical and cell-based potency coupled with acceptable in vitro metabolic stability that resulted in a favorable in vivo oral pharmacokinetic profile in mouse, rat, and dog. Compound 25 demonstrated reduction of tumor growth rates of established human SW620 colorectal carcinoma xenografts using two different oral dosing schedules. We observed concomitant inhibition of a target engagement biomarker phospho-STAT $1^{\text {SER727 }}$ consistent with pharmacokinetic exposure.

In light of its potent and selective profile coupled with good oral pharmacokinetics and duration of in vivo target engagement on oral dosing, compound 25 (MSC2530818) was selected for progression into further preclinical in vivo animal efficacy and safety studies.

\section{EXPERIMENTAL SECTION}

Chemistry. Commercially available starting materials, reagents, and dry solvents were used as supplied. Column chromatography was performed on a CombiFlash Companion purification system using Teledyne Isco silica cartridges. Preparative TLC was performed on Merck plates. Preparative HPLC was conducted according the following methods. Method A: injections of the sample were made onto a SunFire C18 OBD column (100 $\mathrm{A}, 5 \mu \mathrm{m}, 30 \mathrm{~mm} \times 100 \mathrm{~mm}$ ). Chromatographic separation at room temperature was carried out using Agilent Technologies, 1260 Infinity, acetonitrile:water gradient (both modified with $0.1 \%$ trifluoroacetic acid) at a flow rate of $50 \mathrm{~mL} /$ min. Chiral preparative HPLC was conducted according the following methods. Method B: Injections of the sample were made onto a ChiralPak AD-H column $(5 \mu \mathrm{m}, 4.6 \mathrm{~mm} \times 250 \mathrm{~mm})$. Chiral chromatographic separation was carried at room temperature out using SFC Berger Minigram, $\mathrm{CO}_{2} /$ methanol $(85: 15)+0.5 \%$ diethyl amine at a flow rate of $5 \mathrm{~mL} / \mathrm{min}$. Method C: Injections of the sample were made onto a ChiralPak AS-H column $(5 \mu \mathrm{m}, 4.6 \mathrm{~mm} \times 250 \mathrm{~mm})$. Chiral chromatographic separation was carried at room temperature out using SFC Berger Minigram, $\mathrm{CO}_{2} /$ methanol (60:40), modified with $0.5 \%$ diethyl amine, at a flow rate of $5 \mathrm{~mL} / \mathrm{min}$. Method $\mathrm{D}$ : Injections of the sample were made onto a ChiralPak $\mathrm{AD}-\mathrm{H}$ column (5 $\mu \mathrm{m}, 4.6 \mathrm{~mm} \times 250 \mathrm{~mm}$ ). Chiral chromatographic separation was carried at room temperature out using SFC Berger Minigram, $\mathrm{CO}_{2} /$ methanol $(75: 25)+0.5 \%$ diethyl amine, at a flow rate of $5 \mathrm{~mL} / \mathrm{min}$. Additional methods are directly described in the procedures. ${ }^{1} \mathrm{H}$ NMR spectra were recorded on a Bruker Avance-500, Avance 400, Avance II 400, or Avance 300. Samples were prepared as solutions in a deuterated solvent and referenced to the appropriate internal nondeuterated solvent peak. ${ }^{13} \mathrm{C}$ NMR spectra were recorded at 101 $\mathrm{MHz}$ using an internal deuterium lock. The following internal references were used: $\mathrm{CDCl}_{3}, \mathrm{CD}_{3} \mathrm{OD}$, and DMSO- $d_{6}$. LC/MS and HRMS analysis was performed on an Agilent 1200 series HPLC and diode array detector coupled to a 6210 time-of-flight mass spectrometer with dual multimode APCI/ESI source. Analytical separation was carried out according to the following method. Method E: Analytical separation was carried out on a Chromolith Speed ROD column (RP-18e, $50 \mathrm{~mm} \times 4.6 \mathrm{~mm}$ ) using a flow rate of $2.4 \mathrm{~mL} / \mathrm{min}$ in a 3.9 min gradient elution with detection at $220 \mathrm{~nm}$. The mobile phase was a mixture of water containing $0.05 \%$ formic acid (solvent $\mathrm{A}$ ) and acetonitrile containing $0.04 \%$ formic acid (solvent B). Gradient elution was as follows: 95:5 (A/B) to 0:100 (A/B) over $2.8 \mathrm{~min}, 0: 100$ (A/B) for $0.5 \mathrm{~min}$, and then reversion back to $95: 5(\mathrm{~A} / \mathrm{B})$ over 0.1 min, finally 95:5 (A/B) for $0.5 \mathrm{~min}$. LC/MS and HRMS analysis was also performed on a SHIMADZU LC-MS machine consisting of an UFLC 20-AD system with a LC-20 AD pump, SPD-M20A UV detector, and a LCMS 2020 MS detector. Method F: analytical separation was carried out on a Shim-pack XR-ODS column $(2.2 \mu \mathrm{M}$, $3.0 \mathrm{~mm} \times 50 \mathrm{~mm}$ ) using a flow rate of $1.0 \mathrm{~mL} / \mathrm{min}$ in a $3.6 \mathrm{~min}$ gradient elution with detection at $220 \mathrm{~nm}$. The mobile phase was a mixture of water (solvent A) and acetonitrile (solvent B), both containing $0.05 \%$ TFA. Gradient elution was as follows: 95:5 (A/B) over $0.01 \mathrm{~min}$, then $95: 5$ to $0: 100(\mathrm{~A} / \mathrm{B})$ over $2.2 \mathrm{~min}, 0: 100(\mathrm{~A} / \mathrm{B})$ for $1.0 \mathrm{~min}$, and then reversion back to $99: 5(\mathrm{~A} / \mathrm{B})$ over $0.1 \mathrm{~min}$. Method G: analytical separation was carried out on a Shim-pack VPODS column $(2.2 \mu \mathrm{M}, 3.0 \mathrm{~mm} \times 50 \mathrm{~mm})$ using a flow rate of $1.0 \mathrm{~mL} /$ $\mathrm{min}$ in a $5.6 \mathrm{~min}$ gradient elution with detection at $220 \mathrm{~nm}$. The mobile phase was a mixture of water (solvent A) and acetonitrile (solvent B), both containing $0.05 \%$ TFA. Gradient elution was as follows: $95: 5(\mathrm{~A} / \mathrm{B})$ over $0.01 \mathrm{~min}$, then $95: 5$ to $0: 100(\mathrm{~A} / \mathrm{B})$ over 4.2 min, 0:100 (A/B) for $1.0 \mathrm{~min}$, and then reversion back to $99: 5(\mathrm{~A} / \mathrm{B})$ over $0.1 \mathrm{~min}$. Method H: LC/MS and HRMS analysis was performed on a Waters Acquity UPLC and diode array detector coupled to a Waters G2 QToF mass spectrometer fitted with a multimode ESI/ APCI source. Analytical separation was carried out at $30{ }^{\circ} \mathrm{C}$ on a Phenomenex Kinetex XB-C18 column $(30 \mathrm{~mm} \times 2.1 \mathrm{~mm}, 1.7 \mathrm{u}, 100 \mathrm{~A})$ using a flow rate of $0.5 \mathrm{~mL} / \mathrm{min}$ in a 2 min gradient elution with detection at $254 \mathrm{~nm}$. The mobile phase was a mixture of methanol (solvent A) and water (solvent B), both containing formic acid at $0.1 \%$. Gradient elution was as follows: 10:90 (A/B) to 90:10 (A/B) over $1.25 \mathrm{~min}, 90: 10(\mathrm{~A} / \mathrm{B})$ for $0.5 \mathrm{~min}$, and then reversion back to 10:90 (A/B) over $0.15 \mathrm{~min}$, finally 10:90 (A/B) for $0.1 \mathrm{~min}$. Method I: LC/MS and HRMS analysis was performed on an Agilent 1200 series HPLC and diode array detector coupled to a 6210 time-of-flight mass spectrometer with dual multimode APCI/ESI source. Analytical separation was carried out at $30{ }^{\circ} \mathrm{C}$ on a Merck Purospher STAR column $(\mathrm{RP}-18 \mathrm{e}, 30 \mathrm{~mm} \times 4 \mathrm{~mm})$ using a flow rate of $1.5 \mathrm{~mL} / \mathrm{min}$ in a 4 min gradient elution with detection at $254 \mathrm{~nm}$. The mobile phase was a mixture of methanol (solvent A) and water (solvent B), both containing formic acid at $0.1 \%$. Gradient elution was as follows: 10:90 (A/B) to $90: 10(\mathrm{~A} / \mathrm{B})$ over $2.5 \mathrm{~min}, 90: 10(\mathrm{~A} / \mathrm{B})$ for $1 \mathrm{~min}$, and then reversion back to $10: 90(\mathrm{~A} / \mathrm{B})$ over $0.3 \mathrm{~min}$, finally $10: 90(\mathrm{~A} / \mathrm{B})$ for $0.2 \mathrm{~min}$. The following references masses were used for HRMS analysis: caffeine $[\mathrm{M}+\mathrm{H}]^{+}$195.087652; (hexakis $(1 \mathrm{H}, 1 \mathrm{H}, 3 \mathrm{H}-$ tetrafluoropentoxy)phosphazene $[\mathrm{M}+\mathrm{H}]^{+}$922.009798) and hexakis(2,2-difluoroethoxy)phosphazene $[\mathrm{M}+\mathrm{H}]^{+} 622.02896$ or reserpine $[\mathrm{M}+\mathrm{H}]^{+}$609.280657. All compounds submitted for biological testing were determined to be $>95 \%$ pure by methods $\mathrm{E}, \mathrm{F}$, or G unless stated otherwise.

The synthesis of the two key compounds 13 and 25 will be described in the following. The synthesis of the remaining compounds can be found in the Supporting Information.

(3-Amino-1H-indazol-5-yl)-[(2S)-2-(4-chlorophenyl)pyrrolidin-1yl]methanone (13). To a solution of 3-amino- $1 H$-indazole-5carboxylic acid ( $50 \mathrm{mg}, 0.28 \mathrm{mmol}$ ), 2-(4-chloro-phenyl)-pyrrolidine hydrochloride $(123 \mathrm{mg}, 0.560 \mathrm{mmol})$ and 4-methylmorpholine $(0.060$ $\mathrm{mL}, 0.58 \mathrm{mmol})$ in $N, N$-dimethyl-formamide $(2 \mathrm{~mL})$ were added $O$ (1H-benzotriazol-1-yl)- $N, N, N^{\prime}, N^{\prime}$-tetramethyluroniumtetrafluoroborate (TBTU, $83 \mathrm{mg}, 0.26 \mathrm{mmol}$ ) and 1-hydroxybenzotriazole hydrate (HOBt, $9 \mathrm{mg}, 0.07 \mathrm{mmol}$ ). The reaction mixture was stirred at $\mathrm{RT}$ for $15 \mathrm{~h}$. Water was added to the mixture, and the resulting precipitate was filtered off and dried in vacuo. The crude product was purified by prep HPLC (method A, acetonitrile/water) to yield $48 \mathrm{mg}(50 \%)$ of (3- 
amino- $1 H$-indazol-5-yl)-[2-(4-chlorophenyl)pyrrolidin-1-yl]methanone as a yellow solid. ${ }^{1} \mathrm{H}$ NMR $\left(400 \mathrm{MHz}, \mathrm{DMSO}-d_{6}\right) \delta$ 11.70-11.38 (m, 1H), 8.31-7.74 (m, 1H), 7.62-6.84 (m, 6H), 5.67$5.27(\mathrm{~m}, 2 \mathrm{H}), 5.16(\mathrm{t}, J=7.0 \mathrm{~Hz}, 1 \mathrm{H}), 4.04-3.47(\mathrm{~m}, 2 \mathrm{H}), 2.44-2.33$ $(\mathrm{m}, 1 \mathrm{H}), 1.96-1.67(\mathrm{~m}, 3 \mathrm{H})$. LC-MS (method C, ESI, $m / z) t_{\mathrm{R}}=$ $1.89 \mathrm{~min}, 341 / 343(\mathrm{M}+\mathrm{H})^{+}$.

Forty-three $\mathrm{mg}$ of the racemic mixture $(0.13 \mathrm{mmol})$ of dissolved in methanol $(0.5 \mathrm{~mL})$ were separated into the contained enantiomerically pure materials by chiral HPLC in $25 \mu \mathrm{L} /$ run portions according to method C to yield in $8.9 \mathrm{mg}(21 \%)$ of (3-amino- $1 H$-indazol-5-yl)[(2S)-2-(4-chlorophenyl)pyrrolidin-1-yl]methanone as a brownish solid and $8.6 \mathrm{mg}(20 \%)$ of (3-amino- $1 H$-indazol-5-yl)-[(2R)-2-(4chlorophenyl)pyrrolidin-1-yl]methanone as a brownish solid. HPLC/ MS (chiral, method C): $R_{\mathrm{t}} 3.47 \mathrm{~min}$ (compd 13), $R_{\mathrm{t}} 6.45 \mathrm{~min}$ (compd ent-13). $S$-enantiomer: ${ }^{1} \mathrm{H}$ NMR (500 MHz, DMSO- $d_{6}$, mixture of rotamers) $\delta 11.62-11.37(\mathrm{bs}, 1 \mathrm{H}), 8.34-7.97(\mathrm{~m}, 1 \mathrm{H}), 7.63-6.88(\mathrm{~m}$, $6 \mathrm{H}), 5.49(\mathrm{~s}, 2 \mathrm{H}), 5.16(\mathrm{t}, J=7.1,1 \mathrm{H}), 3.96-3.52(\mathrm{~m}, 2 \mathrm{H}), 2.44-2.33$ $(\mathrm{m}, 1 \mathrm{H}), 1.95-1.68(\mathrm{~m}, 3 \mathrm{H}) .{ }^{13} \mathrm{C}$ NMR (101 MHz, DMSO-d 6,3 signals missing) $\delta 169.4,150.0,143.4,141.6,130.8,128.1,127.4,125.9$, $120.9,113.2,108.8,60.1,51.0,34.7,25.1$. LC-MS (method E, ESI, $m$ / z) $t_{\mathrm{R}}=1.89 \mathrm{~min}, 341 / 343(\mathrm{M}+\mathrm{H})^{+}$. ESI-HRMS calcd for $\mathrm{C}_{18} \mathrm{H}_{18}{ }^{35} \mathrm{ClN}_{4} \mathrm{O}(\mathrm{M}+\mathrm{H})^{+}$, 341.1164; found, 341.1176.

[(2S)-2-(4-chlorophenyl)pyrrolidin-1-yl]-(3-methyl-1H-pyrazolo$[3,4-b]$ pyridin-5-yl)methanone (25). Into a $50 \mathrm{~mL}$ round-bottom flask, 3-methyl-1H-pyrazolo[3,4-b]pyridine-5-carboxylic acid (0.500 g, $2.74 \mathrm{mmol}),(S)$-2-(4-chloro-phenyl)-pyrrolidine hydrochloride $(0.720$ g, $3.29 \mathrm{mmol}), \mathrm{N}$-(3-(dimethylamino)propyl)- $\mathrm{N}^{\prime}$-ethylcarbodiimide $(1.06 \mathrm{~g}, 5.48 \mathrm{mmol})$, and 1-hydroxybenzotriazole hydrate $(0.380 \mathrm{~g}$, $2.74 \mathrm{mmol}$ ) were weighed in and dissolved in $\mathrm{N}, \mathrm{N}$-dimethylformamide $(10 \mathrm{~mL})$. 4-Methylmorpholine $(0.920 \mathrm{~mL}, 8.21 \mathrm{mmol})$ was added at $\mathrm{RT}$, and stirring was continued for $30 \mathrm{~min}$ at the same temperature. The mixture was poured into a mixture of brine and water $(1: 1,150$ $\mathrm{mL})$. The resulting beige precipitate was filtered, washed with water, and dried at $60{ }^{\circ} \mathrm{C}$ overnight to give $640 \mathrm{mg}(69 \%)$ of [(2S)-2-(4chlorophenyl)pyrrolidin-1-yl]-(3-methyl-1 $H$-pyrazolo[3,4-b]pyridin-5yl)methanone as beige solid. ${ }^{1} \mathrm{H}$ NMR (400 MHz, DMSO- $\left.d_{6}\right) \delta$ $13.51-13.19(\mathrm{~m}, 1 \mathrm{H}), 8.76-6.96(\mathrm{~m}, 6 \mathrm{H}), 5.25-4.95(\mathrm{~m}, 1 \mathrm{H}), 4.03-$ $3.51(\mathrm{~m}, 2 \mathrm{H}), 2.62-2.28(\mathrm{~m}, 4 \mathrm{H}), 2.00-1.68(\mathrm{~m}, 3 \mathrm{H}) .{ }^{13} \mathrm{C} \mathrm{NMR}$ (101 MHz, DMSO- $d_{6}, 1$ signal missing) $\delta 167.3,152.4,148.1,146.9$, 143.0, 142.1, 130.9, 129.1, 128.1, 127.6, 124.9, 112.8, 60.4, 50.7, 34.8, 24.9, 12.2. LC-MS (method E, ESI, $m / z) t_{\mathrm{R}}=1.99 \mathrm{~min}, 341 / 343(\mathrm{M}$ $+\mathrm{H})^{+}$. ESI-HRMS calcd for $\mathrm{C}_{18} \mathrm{H}_{18}{ }^{35} \mathrm{ClN}_{4} \mathrm{O}(\mathrm{M}+\mathrm{H})^{+}, 341.1164$; found, 341.1167 .

All other experimental details (mouse, rat, and human $\mathrm{Cl}_{\text {int }}$ determination; Caco-2 determination; in vivo mouse $\mathrm{PK}$ in-life phase; in vivo rat and dog PK in-life phase; bioanalytics; prediction of human clearance; in vitro cell-based reporter assays, $7 \mathrm{dF} 3$ luciferase reporter assay; in vitro biochemical assays, CDK8 Lanthascreen binding assay and reporter displacement assay for CDK19; human tumor xenograft efficacy study; pharmacokinetic analysis; tumor xenograft processing; and Luminex analysis) are described in previous publications. ${ }^{27,30}$ All animal experiments were conducted in accordance with local and United Kingdom National Cancer Research Institute guidelines. ${ }^{47}$

\section{ASSOCIATED CONTENT}

\section{S Supporting Information}

The Supporting Information is available free of charge on the ACS Publications website at DOI: 10.1021/acs.jmedchem.6b00597.

Synthesis protocols and analytical data; crystallographic data of compounds 6,17 , and 25; kinase selectivity data for compounds 13 and 25; activity of compound 25 tested at $10 \mu \mathrm{M}$ across a panel of 59 receptors and ion channels (CEREP) and Omit maps (PDF)

\section{Accession Codes}

Atomic coordinates and structure factors for the crystal structures of $\mathrm{CDK} 8 /$ cyclin $\mathrm{C}$ with compounds $\mathbf{6 , 1 7}$, and $\mathbf{2 5}$ can be accessed using PDB codes 5ICP, 5IDP, and 5IDN, respectively.

\section{AUTHOR INFORMATION}

\section{Corresponding Authors}

*For P.Cz.: E-mail: paul.czodrowski@merckgroup.com.

*For K.S.: E-mail: kai.schiemann@merckgroup.com.

\section{Author Contributions}

The manuscript was written with contributions of all authors. All authors have given approval to the final version of the manuscript.

\section{Notes}

The authors declare the following competing financial interest(s): A.M., S.A.E., M.-J.O.-R., F.I.R, P.A.C. and J.B. are current or former employees of The Institute of Cancer Research, which has a commercial interest in the development of WNT pathway inhibitors. P.Cz. D.W., C.E., O.P., M.B., F.R., R.S., D.M., D.S., K.U. and K.S., are current employees of Merck KGaA.

\section{ACKNOWLEDGMENTS}

We thank Dr. Amin Mirza, Meirion Richards, and Dr. Maggie Liu for their assistance with NMR, mass spectrometry, and HPLC, and Gary Nugent and Dr. Christian Herhaus for chemoinformatics support. We thank the team of Proteros Biostructures $\mathrm{GmbH}$, Bunsenstrasse 7a, D-82152 Martinsried, Germany, for the reporter displacement assay and, in particular, Dr. Elisabeth V. Schneider and Dr. Alfred Lammens for the Xray crystal structures with $\mathrm{CDK} 8 /$ cyclinC. This work was supported by Cancer Research UK [grant no. C309/A11566]. We acknowledge NHS funding to the NIHR Biomedical Research Centre at The Institute of Cancer Research and The Royal Marsden.

\section{ABBREVIATIONS USED}

$\mathrm{CDK}$, cyclin-dependent kinase; $\mathrm{Cl}$, clearance; $\mathrm{CL}_{\text {int }}$ intrinsic clearance; ER, efflux ratio; F, bioavailability; FaSSIF, fasted-state simulated intestinal fluid; FeSSIF, fed state simulated intestinal fluid; GSK $3 \alpha$, glycogen synthase kinase 3alpha; $P_{\text {app }}$, apparent permeability; $t_{1 / 2}$, half-life; $\mathrm{Vd}_{\mathrm{s}}$, apparent volume of distribution at steady state; vdW, van der Waals

\section{REFERENCES}

(1) Tsutsui, T.; Fukasawa, R.; Tanaka, A.; Hirose, Y.; Ohkuma, Y. Identification of Target Genes for the CDK Subunits of the Mediator Complex. Genes Cells 2011, 16 (12), 1208-1218.

(2) Galbraith, M. D.; Donner, A. J.; Espinosa, J. M. CDK8: A Positive Regulator of Transcription. Transcription 2010, 1 (1), 4-12.

(3) Firestein, R.; Hahn, W. C. Revving the Throttle on an Oncogene: CDK8 Takes the Driver Seat. Cancer Res. 2009, 69 (20), 7899-7901.

(4) Taatjes, D. J. The Human Mediator Complex: A Versatile, Genome-Wide Regulator of Transcription. Trends Biochem. Sci. 2010, 35 (6), 315-322.

(5) Allen, B. L.; Taatjes, D. J. The Mediator Complex: A Central Integrator of Transcription. Nat. Rev. Mol. Cell Biol. 2015, 16 (3), $155-166$.

(6) Kim, S.; Xu, X.; Hecht, A.; Boyer, T. G. Mediator Is a Transducer of Wnt/ $\beta$-Catenin Signaling. J. Biol. Chem. 2006, 281 (20), 1406614075 .

(7) Schiano, C.; Casamassimi, A.; Rienzo, M.; de Nigris, F.; Sommese, L.; Napoli, C. Involvement of Mediator Complex in 
Malignancy. Biochim. Biophys. Acta, Rev. Cancer 2014, 1845 (1), 6683.

(8) Rickert, P.; Seghezzi, W.; Shanahan, F.; Cho, H.; Lees, E. Cyclin C/CDK8 Is a Novel CTD Kinase Associated with RNA Polymerase II. Oncogene 1996, 12 (12), 2631-2640.

(9) Bancerek, J.; Poss, Z. C.; Steinparzer, I.; Sedlyarov, V.; Pfaffenwimmer, T.; Mikulic, I.; Dölken, L.; Strobl, B.; Müller, M.; Taatjes, D. J.; Kovarik, P. CDK8 Kinase Phosphorylates Transcription Factor STAT1 to Selectively Regulate the Interferon Response. Immunity 2013, 38 (2), 250-262.

(10) Morris, E. J.; Ji, J.-Y.; Yang, F.; Di Stefano, L.; Herr, A.; Moon, N.-S.; Kwon, E.-J.; Haigis, K. M.; Näär, A. M.; Dyson, N. J. E2F1 Represses $\beta$-Catenin Transcription and Is Antagonized by Both pRB and CDK8. Nature 2008, 455 (7212), 552-556.

(11) Zhao, J.; Ramos, R; Demma, M. CDK8 Regulates E2F1 Transcriptional Activity through S375 Phosphorylation. Oncogene 2013, 32 (30), 3520-3530.

(12) Fryer, C. J.; White, J. B.; Jones, K. A. Mastermind Recruits CycC:CDK8 to Phosphorylate the Notch ICD and Coordinate Activation with Turnover. Mol. Cell 2004, 16 (4), 509-520.

(13) Alarcón, C.; Zaromytidou, A.-I.; Xi, Q.; Gao, S.; Yu, J.; Fujisawa, S.; Barlas, A.; Miller, A. N.; Manova-Todorova, K.; Macias, M. J.; Sapkota, G.; Pan, D.; Massagué, J. Nuclear CDKs Drive Smad Transcriptional Activation and Turnover in BMP and TGF- $\beta$ Pathways. Cell 2009, 139 (4), 757-769.

(14) Zhao, X.; Feng, D.; Wang, Q.; Abdulla, A.; Xie, X.-J.; Zhou, J.; Sun, Y.; Yang, E. S.; Liu, L.-P.; Vaitheesvaran, B.; Bridges, L.; Kurland, I. J.; Strich, R.; Ni, J.-Q.; Wang, C.; Ericsson, J.; Pessin, J. E.; Ji, J.-Y.; Yang, F. Regulation of Lipogenesis by Cyclin-Dependent Kinase 8Mediated Control of SREBP-1. J. Clin. Invest. 2012, 122 (7), 24172427.

(15) Adler, A. S.; McCleland, M. L.; Truong, T.; Lau, S.; Modrusan, Z.; Soukup, T. M.; Roose-Girma, M.; Blackwood, E. M.; Firestein, R. CDK8 Maintains Tumor Dedifferentiation and Embryonic Stem Cell Pluripotency. Cancer Res. 2012, 72 (8), 2129-2139.

(16) Firestein, R.; Bass, A. J.; Kim, S. Y.; Dunn, I. F.; Silver, S. J.; Guney, I.; Freed, E.; Ligon, A. H.; Vena, N.; Ogino, S.; Chheda, M. G.; Tamayo, P.; Finn, S.; Shrestha, Y.; Boehm, J. S.; Jain, S.; Bojarski, E.; Mermel, C.; Barretina, J.; Chan, J. A.; Baselga, J.; Tabernero, J.; Root, D. E.; Fuchs, C. S.; Loda, M.; Shivdasani, R. A.; Meyerson, M.; Hahn, W. C. CDK8 Is a Colorectal Cancer Oncogene That Regulates $\beta$ Catenin Activity. Nature 2008, 455 (7212), 547-551.

(17) Firestein, R.; Shima, K.; Nosho, K.; Irahara, N.; Baba, Y.; Bojarski, E.; Giovannucci, E. L.; Hahn, W. C.; Fuchs, C. S.; Ogino, S. CDK8 Expression in 470 Colorectal Cancers in Relation to $\beta$-Catenin Activation, Other Molecular Alterations and Patient Survival. Int. J. Cancer 2010, 126 (12), 2863-2873.

(18) Kapoor, A.; Goldberg, M. S.; Cumberland, L. K.; Ratnakumar, K.; Segura, M. F.; Emanuel, P. O.; Menendez, S.; Vardabasso, C.; Leroy, G.; Vidal, C. I.; Polsky, D.; Osman, I.; Garcia, B. A.; Hernando, E.; Bernstein, E. The Histone Variant macroH2A Suppresses Melanoma Progression through Regulation of CDK8. Nature 2010, 468 (7327), 1105-1109.

(19) Fryer, C. J.; White, J. B.; Jones, K. A. Mastermind Recruits CycC:CDK8 to Phosphorylate the Notch ICD and Coordinate Activation with Turnover. Mol. Cell 2004, 16 (4), 509-520.

(20) Li, N.; Fassl, A.; Chick, J.; Inuzuka, H.; Li, X.; Mansour, M. R.; Liu, L.; et al. Cyclin C is a haploinsufficient tumour suppressor. Nat. Cell Biol. 2014, 16, 1080-1091.

(21) Porter, D. C.; Farmaki, E.; Altilia, S.; Schools, G. P.; West, D. K.; Chen, M.; Chang, B.-D.; Puzyrev, A. T.; Lim, C.; Rokow-Kittell, R.; Friedhoff, L. T.; Papavassiliou, A. G.; Kalurupalle, S.; Hurteau, G.; Shi, J.; Baran, P. S.; Gyorffy, B.; Wentland, M. P.; Broude, E. V.; Kiaris, H.; Roninson, I. B. Cyclin-Dependent Kinase 8 Mediates ChemotherapyInduced Tumor-Promoting Paracrine Activities. Proc. Natl. Acad. Sci. U. S. A. 2012, 109 (34), 13799-13804.

(22) Westerling, T.; Kuuluvainen, E.; Mäkelä, T. P. Cdk8 Is Essential for Preimplantation Mouse Development. Mol. Cell. Biol. 2007, 27 (17), 6177-6182.
(23) Kim, M.-Y.; Han, S. I.; Lim, S.-C. Roles of Cyclin-Dependent Kinase 8 and $\beta$-Catenin in the Oncogenesis and Progression of Gastric Adenocarcinoma. Int. J. Oncol. 2011, 38 (5), 1375-1383.

(24) Rzymski, T.; Mikula, M.; Wiklik, K.; Brzózka, K. CDK8 KinaseAn Emerging Target in Targeted Cancer Therapy. Biochim. Biophys. Acta, Proteins Proteomics 2015, 1854 (10 Pt B), 1617-1629.

(25) Pelish, H. E.; Liau, B. B.; Nitulescu, I. I.; Tangpeerachaikul, A.; Poss, Z. C.; Da Silva, D. H.; Caruso, B. T.; Arefolov, A.; Fadeyi, O.; Christie, A. L.; Du, K.; Banka, D.; Schneider, E. V.; Jestel, A.; Zou, G.; Si, C.; Ebmeier, C. C.; Bronson, R. T.; Krivtsov, A. V.; Myers, A. G.; Kohl, N. E.; Kung, A. L.; Armstrong, S. A.; Lemieux, M. E.; Taatjes, D. J.; Shair, M. D. Mediator Kinase Inhibition Further Activates SuperEnhancer-Associated Genes in AML. Nature 2015, 526 (7572), 273276.

(26) Mallinger, A.; Crumpler, S.; Pichowicz, M.; Waalboer, D.; Stubbs, M.; Adeniji-Popoola, O.; Wood, B.; Smith, E.; Thai, C.; Henley, A. T.; Georgi, K.; Court, W.; Hobbs, S.; Box, G.; Ortiz-Ruiz, M.-J.; Valenti, M.; De Haven Brandon, A.; TePoele, R.; Leuthner, B.; Workman, P.; Aherne, W.; Poeschke, O.; Dale, T.; Wienke, D.; Esdar, C.; Rohdich, F.; Raynaud, F.; Clarke, P. A.; Eccles, S. A.; Stieber, F.; Schiemann, K.; Blagg, J. Discovery of Potent, Orally Bioavailable, Small-Molecule Inhibitors of WNT Signaling from a Cell-Based Pathway Screen. J. Med. Chem. 2015, 58 (4), 1717-1735.

(27) Mallinger, A.; Schiemann, K.; Rink, C.; Stieber, F.; Calderini, M.; Crumpler, S.; Stubbs, M.; Adeniji-Popoola, O.; Poeschke, O.; Busch, M.; Czodrowski, P.; Musil, D.; Schwarz, D.; Ortiz-Ruiz, M.-J.; Schneider, R.; Thai, C.; Valenti, M.; de Haven Brandon, A.; Burke, R.; Workman, P.; Dale, T.; Wienke, D.; Clarke, P. A.; Esdar, C.; Raynaud, F. I.; Eccles, S. A.; Rohdich, F.; Blagg, J. Discovery of Potent, Selective, and Orally Bioavailable Small-Molecule Modulators of the Mediator Complex-Associated Kinases CDK8 and CDK19. J. Med. Chem. 2016, 59 (3), 1078-1101.

(28) Schiemann, K.; Mallinger, A.; Wienke, D.; Esdar, C.; Poeschke, O.; Busch, M.; Rohdich, F.; Eccles, S. A.; Schneider, R.; Raynaud, F. I.; Czodrowski, P.; Musil, D.; Schwarz, D.; Urbahns, K.; Blagg, J. Discovery of Potent and Selective CDK8 Inhibitors from an HSP90 Pharmacophore. Bioorg. Med. Chem. Lett. 2016, 26 (5), 1443-1451.

(29) Dale, T.; Clarke, P. A.; Esdar, C.; Waalboer, D.; AdenijiPopoola, O.; Ortiz-Ruiz, M.-J.; Mallinger, A.; Samant, R. S.; Czodrowski, P.; Musil, D.; Schwarz, D.; Schneider, K.; Stubbs, M.; Ewan, K.; Fraser, E.; TePoele, R.; Court, W.; Box, G.; Valenti, M.; de Haven Brandon, A.; Gowan, S.; Rohdich, F.; Raynaud, F.; Schneider, R.; Poeschke, O.; Blaukat, A.; Workman, P.; Schiemann, K.; Eccles, S. A.; Wienke, D.; Blagg, J. A Selective Chemical Probe for Exploring the Role of CDK8 and CDK19 in Human Disease. Nat. Chem. Biol. 2015, 11 (12), 973-980.

(30) Mallinger, A.; Schiemann, K.; Rink, C.; Sejberg, J.; Honey, M. A.; Czodrowski, P.; Stubbs, M.; Poeschke, O.; Busch, M.; Schneider, R.; Schwarz, D.; Musil, D.; Burke, R.; Urbahns, K.; Workman, P.; Wienke, D.; Clarke, P. A.; Raynaud, F. I.; Eccles, S. A.; Esdar, C.; Rohdich, F.; Blagg, J. 2,8-Disubstituted-1,6-Naphthyridines and 4,6Disubstituted-Isoquinolines with Potent, Selective Affinity for CDK8/ 19. ACS Med. Chem. Lett. 2016, 7, 573-578.

(31) Ewan, K.; Pajak, B.; Stubbs, M.; Todd, H.; Barbeau, O.; Quevedo, C.; Botfield, H.; Young, R.; Ruddle, R.; Samuel, L.; Battersby, A.; Raynaud, F.; Allen, N.; Wilson, S.; Latinkic, B.; Workman, P.; McDonald, E.; Blagg, J.; Aherne, W.; Dale, T. A Useful Approach to Identify Novel Small-Molecule Inhibitors of WntDependent Transcription. Cancer Res. 2010, 70 (14), 5963-5973.

(32) SZMAP 1.2; OpenEye Scientific Software: Santa Fe, NM, 2013.

(33) Abel, R.; Young, T.; Farid, R.; Berne, B. J.; Friesner, R. A. Role of the Active-Site Solvent in the Thermodynamics of Factor Xa Ligand Binding. J. Am. Chem. Soc. 2008, 130 (9), 2817-2831.

(34) Baker, N. A. Improving Implicit Solvent Simulations: A PoissonCentric View. Curr. Opin. Struct. Biol. 2005, 15 (2), 137-143.

(35) Koehl, P. Electrostatics Calculations: Latest Methodological Advances. Curr. Opin. Struct. Biol. 2006, 16 (2), 142-151.

(36) Mortier, J.; Rakers, C.; Bermudez, M.; Murgueitio, M. S.; Riniker, S.; Wolber, G. The Impact of Molecular Dynamics on Drug 
Design: Applications for the Characterization of Ligand-Macromolecule Complexes. Drug Discovery Today 2015, 20 (6), 686-702.

(37) Lazaridis, T. Inhomogeneous Fluid Approach to Solvation Thermodynamics. 1. Theory. J. Phys. Chem. B 1998, 102 (18), 35313541.

(38) Czodrowski, P.; Hölzemann, G.; Barnickel, G.; Greiner, H.; Musil, D. Selection of Fragments for Kinase Inhibitor Design: Decoration Is Key. J. Med. Chem. 2015, 58 (1), 457-465.

(39) Kohlmann, A.; Zhu, X.; Dalgarno, D. Application of MM-GB/ SA and WaterMap to SRC Kinase Inhibitor Potency Prediction. ACS Med. Chem. Lett. 2012, 3 (2), 94-99.

(40) Robinson, D. D.; Sherman, W.; Farid, R. Understanding Kinase Selectivity through Energetic Analysis of Binding Site Waters. ChemMedChem 2010, 5 (4), 618-627.

(41) Bortolato, A.; Tehan, B. G.; Bodnarchuk, M. S.; Essex, J. W.; Mason, J. S. Water Network Perturbation in Ligand Binding: Adenosine A(2A) Antagonists as a Case Study. J. Chem. Inf. Model. 2013, 53 (7), 1700-1713.

(42) Grädler, U.; Czodrowski, P.; Tsaklakidis, C.; Klein, M.; Werkmann, D.; Lindemann, S.; Maskos, K.; Leuthner, B. StructureBased Optimization of Non-Peptidic Cathepsin D Inhibitors. Bioorg. Med. Chem. Lett. 2014, 24 (17), 4141-4150.

(43) Bayden, A. S.; Moustakas, D. T.; Joseph-McCarthy, D.; Lamb, M. L. Evaluating Free Energies of Binding and Conservation of Crystallographic Waters Using SZMAP. J. Chem. Inf. Model. 2015, 55 (8), 1552-1565.

(44) Zoidis, G.; Giannakopoulou, E.; Stevaert, A.; Frakolaki, E.; Myrianthopoulos, V.; Fytas, G.; Mavromara, P.; Mikros, E.; Bartenschlager, R.; Vassilaki, N.; Naesens, L. Novel Indole-flutimide Heterocycles with Activity against Influenza PA Endonuclease and Hepatitis C Virus. MedChem Comm 2016, 7 (3), 447-456.

(45) Volkamer, A.; Eid, S.; Turk, S.; Rippmann, F.; Fulle, S. Identification and Visualization of Kinase-Specific Subpockets. J. Chem. Inf. Model. 2016, 56 (2), 335-346.

(46) Neumann, L.; von König, K.; Ullmann, D. HTS Reporter Displacement Assay for Fragment Screening and Fragment Evolution toward Leads with Optimized Binding Kinetics, Binding Selectivity, and Thermodynamic Signature. Methods Enzymol. 2011, 493, 299320.

(47) Workman, P.; Aboagye, E. O.; Balkwill, F.; Balmain, A.; Bruder, G.; Chaplin, D. J.; Double, J. A.; Everitt, J.; Farningham, D. A. H.; Glennie, M. J.; Kelland, L. R.; Robinson, V.; Stratford, I. J.; Tozer, G. M.; Watson, S.; Wedge, S. R.; Eccles, S. A. Committee of the National Cancer Research Institute. Guidelines for the Welfare and Use of Animals in Cancer Research. Br. J. Cancer 2010, 102 (11), 1555-1577. 